\title{
Noun-Phrase Structure by Reprojection
}

\author{
Doreen Georgi and Gereon Müller
}

\begin{abstract}
In this paper we argue that the concept of reprojection, often applied in the verbal domain, should be extended to the nominal domain. We develop an analysis according to which a moved $\mathrm{N}$ does not adjoin to a functional category; rather, it moves out of its projection and remerges with it. This movement is (indirectly) triggered by a certain kind of categorial probe feature that we call a "Münchhausen feature" (Fanselow 2003). In this way, conceptual problems resulting from head movement conceived as adjunction of one head to another are avoided. Furthermore, one of the main arguments for $\mathrm{D}$ as the head of the nominal projection (namely, that evidence for N movement is also evidence for DP on top of NP) is refuted. In addition to showing that an NP approach to nominal projections is viable (given reprojection), we also provide one independent argument for it: the reprojection approach to NP structure turns out to automatically derive a core assumption that must otherwise be stipulated in the theories of word-order variation in nominal projections developed by Cinque (2005) and Abels \& Neeleman (2006) (namely, that only those projections can undergo movement within nominal projections that contain $\mathrm{N}$ ).
\end{abstract}

\section{Introduction}

Head movement is required within the nominal projection for both empirical and conceptual reasons. To give just a few examples: Ritter (1988) argues for $\mathrm{N}$ movement in construct-state nominals in Hebrew, Longobardi (1994) gives convincing arguments for head movement of proper names in Romance languages, and Abels \& Neeleman (2006) need it to derive the typology of word order within NP. Chomsky (2007) argues that there is a functional category $\mathrm{n}$ that c-commands $\mathrm{N}$ and acts as the head of the nominal projection (rather than $\mathrm{D}$ ). $\mathrm{N}$ raises to $\mathrm{n}$, just as $\mathrm{V}$ raises to $\mathrm{v}$ in the verbal projection. ${ }^{1}$

However, the conception of head movement as adjunction of one head to another creates several problems with respect to highly general (and independently motivated) constraints on movement, for example, the Extension Condition (Chomsky 1995) or the (related) c-command requirement for traces; see Brody 2001, Mahajan 2001, Müller 2004, and Matushansky 2006 (among others) for relevant discussion. Requirements such as these cannot be fulfilled by head movement as adjunction unless one is prepared to invoke extra concepts (compare, e.g., Baker's [1988] more liberal notion of c-command, which deviates substantially from what is the simplest version of the concept: $\alpha$ c-commands $\beta$ iff $\beta$ is, or is included in, the sister of $\alpha$ ).

For helpful comments and discussion, we would like to thank three reviewers for Syntax, Klaus Abels, Artemis Alexiadou, Petr Biskup, Ellen Brandner, Stefan Keine, Uli Lutz, Marc Richards, Florian Schäfer, and especially Fabian Heck. We are also grateful to the participants of a course on DP structure at Universität Leipzig (winter term 2006/2007), and the audience of the GGS meeting at Universität Konstanz (May 2007). This work was supported by a DFG grant to the project Argument Encoding in Morphology and Syntax, as part of Forschergruppe 742.

${ }^{1}$ This is motivated by the assumption that verbal and nominal projections are structurally similar. Still, the semantic motivation of the phonologically empty categories $\mathrm{v}$ and $\mathrm{n}$ is questionable (for discussion, see Larson 2004). 
Another principle that is systematically violated by head movement as adjunction to a higher head is Abels's (2003) Anti-Locality Constraint, which excludes attraction of a head by a c-commanding head as an operation that is too local. Thus, there is a dilemma: on the one hand, there is good evidence for head movement in nominal projections; on the other hand, the standard view of head movement as adjunction to the next higher head is incompatible with several well-established constraints on displacement.

A way out is to treat head movement as reprojection: a head $\mathrm{H}$ moves out of a phrase $\alpha$ and remerges with $\alpha$, projecting its category label in the derived position. ${ }^{2}$ We would like to contend that it is promising to transfer the concept of reprojection to the nominal domain, where movement of $\mathrm{N}$ to a functional head $(\mathrm{D}$, or $\mathrm{n}$, or something else) is often postulated. It turns out that such a move not only avoids conceptual problems with head movement as adjunction; it also calls into question one of the most important types of argument for a DP-over-NP structure of nominal projections (the DP hypothesis).

Indeed, it seems to us that many of the arguments that were presented in favor of a functional category D that heads the nominal phrase (Abney 1987 and Szabolcsi 1994) have lost their force under minimalist assumptions (Chomsky 1995, 2001, 2005b). For instance, the availability of two separate positions in front of a noun in examples like (1a-b) (in English and Hungarian, respectively) does not provide evidence for a DP outside of NP if a multiple specifier approach is adopted.

(1) a. [NP [the Emperor's] [ $\mathrm{N}^{\prime}[$ every] [N wish]]]

b. $\left[{ }_{N P}[\right.$ Peter $]\left[\mathrm{N}^{\prime}\right.$ [valamannyi] [N kalap-ja $\left.]\right]$

Peter's every hat-DEF

As indicated, both prenominal items can be specifiers of $\mathrm{N}$, given the possibility of multiple specifiers. In the same vein, it seems that many other arguments in support of $\mathrm{D}$ as the head of nominal projections can be shown to be spurious under minimalist assumptions. However, there is one type of argument in favor of the DP hypothesis that has so far resisted a straightforward minimalist elimination: there is strong evidence for movement of $\mathrm{N}$, and if $\mathrm{N}$ moves, there must be a landing site (D) (see

\footnotetext{
${ }^{2}$ Early versions of this concept include Pesetsky 1985, where reprojection after head movement at LF serves to circumvent bracketing paradoxes, and Stechow \& Sternefeld 1988, where German verb-second clauses are treated as reprojections of a moved finite V. Holmberg (1991), Ackema, Neeleman \& Weerman (1993), Koeneman (2000), Haider (2000), Hornstein \& Uriagereka (2002), and Fanselow (2003) argue for reprojection in verb phrases; Bury (2003) and Bayer \& Brandner (2008) apply the concept to wh-CPs, Donati (2006) applies it to free relatives, and Bhatt (2002) to $\mathrm{N}$ raising out of relative clauses (a version of Vergnaud raising, as in Kayne 1994). Surányi (2005) offers a comprehensive theoretical discussion of the issue.
} 
Alexiadou, Haegeman \& Stavrou 2007:87). ${ }^{3}$ The main claim of this paper is that reprojection of $\mathrm{N}$ severely weakens this argument (and, therefore, the DP hypothesis) because no further functional head is needed as a target for movement. ${ }^{4}$

We will proceed as follows. In section 2 we discuss data that lend support to the assumption of $\mathrm{N}$ movement in nominal projections. Section 3 introduces the concept of reprojection and shows how it can be implemented in a derivational approach to grammar along the lines of the Minimalist Program. Next, we illustrate our theory of reprojection by implementing the approach to argument realization in verb phrases in German developed by Haider $(2000,2005,2006)$. Finally, in section 4 we return to nominal projections and show how $\mathrm{N}$ movement by reprojection derives the empirical evidence of section 2. In this context, we address the approach to word-order variation in the nominal projection in Cinque 2005, and particularly the somewhat simpler version of this approach developed by Abels \& Neeleman (2006); and we show how the sole remaining stipulative assumption that Abels \& Neeleman make crucial use of (following Cinque), in their (otherwise simple and elegant) analysis - namely, that only categories including $\mathrm{N}$ can undergo movement in the nominal projection - can be dispensed with under reprojection.

Throughout this paper, we use the term nominal projection in a theory-neutral sense that leaves open the question of whether $\mathrm{D}$ or $\mathrm{N}$ (or, in fact, $\mathrm{n}$ ) is the overall head.

\section{Arguments for $\mathbf{N}$ Movement}

In this section we give an overview of three empirical domains that provide arguments for $\mathrm{N}$ movement and the DP hypothesis, and sum up relevant analyses given in the literature: N movement of proper names in Italian (Longobardi 1994); N movement in construct-state nominals in Hebrew (Ritter 1988); and movement of (a category containing) $\mathrm{N}$ that derives the typology of the orders of noun, determiner, numeral and adjective (Cinque 2005, Abels \& Neeleman 2006). In these analyses (which can to some extent be viewed as representative of a much larger research enterprise), a recurring pattern of argumentation emerges. First, there is evidence for movement of $\mathrm{N}$ to a higher position within the nominal projection. Second, if $\mathrm{N}$ is the head of the nominal projection, there is no such position. Third, consequently,

\footnotetext{
${ }^{3}$ This kind of head movement analysis is criticized by Alexiadou (2001), Shlonsky (2004), and Laenzlinger (2005), motivated not least by the conceptual problems noted above. Sometimes (e.g., in the latter two analyses), (remnant) XP movement has been suggested as an alternative to head movement in nominal projections. Such XP movement approaches typically raise various questions related to overgeneration that we cannot possibly go into here; but assuming that these questions can eventually be answered satisfactorily, we acknowledge that a (remnant) XP movement analysis might qualify as a viable alternative to the analysis in terms of reprojection to be developed below. However, since remnant movement analyses usually rely on a complex system of functional projections on top of a lexical projection (see, e.g., Koopman \& Szabolcsi 2000), adopting a remnant-movement approach would not actually contribute to the enterprise of finding out whether an NP-over-DP analysis can be maintained in the light of evidence for $\mathrm{N}$ displacement (in the pretheoretical sense, i.e., however it is theoretically derived), which is what we are concerned with here.

${ }^{4}$ Alexiadou, Haegeman \& Stavrou (2007) argue that cases of XP fronting within and from nominal projections also provide a strong argument for DP-over-NP structures. We address this issue in section 4.4.
} 
a higher $\mathrm{X}^{0}$ category must be available as a landing site for $\mathrm{N}$ movement. Fourth, this landing site may exhibit characteristic properties of D. Fifth and finally, at least in these cases, the landing site can be assumed to be D, and DP must thus be above NP (minimally, a functional head above NP is needed). If this reasoning is on the right track, then, at least in these environments, NP is a complement of D and the nominal projection is a DP; and if one assumes that selection of nominal arguments obeys categorial uniformity (such that V may not alternatively select DP or NP), then the DP hypothesis must be generalized. ${ }^{5}$

\subsection{N Movement in Italian}

Longobardi (1994) argues for movement of proper names in Italian on the basis of the following observations: Count nouns in the singular that function as arguments must be preceded by a phonologically nonempty determiner. Nouns that are not arguments (in vocative, predicative, or exclamative environments) do not fall under this requirement. The conclusion Longobardi draws from this is that a nominal expression can only be an argument of a predicate if it is introduced by an element of category D. Two problems arise for this simple generalization. First, bare count nouns in the plural and mass nouns show up without a visible determiner.

(2) Ogni giorno mangia patate.

every day eat.3SG potato

'He eats potatoes every day.'

This problem can be solved by assuming that these nouns are combined with an empty D that gives rise to an indefinite interpretation associated with bare plurals and mass terms.

Second, and more importantly in the present context, proper names do not have to be introduced by a determiner, either. However, in this case, the solution cannot be this empty D because (singular) proper names are neither interpreted as plural entities nor are they indefinite. To solve this problem, Longobardi argues that proper names belong to the category $\mathrm{N}$ (an assumption that is supported by the fact that proper names can in principle be preceded by a determiner in Italian); a proper name $\mathrm{N}$ then moves to $\mathrm{D}$, the head of the nominal projection. Strong evidence for this movement comes from the placement of adjectives in nominal projections in Italian. Consider the following examples.

$$
\begin{aligned}
& \text { a. *[DP mio [D' il }\left[{ }_{\mathrm{NP}}[\mathrm{N} \text { Gianni }]\right] \\
& \text { my DEF Gianni } \\
& \text { b. [DP il [NP [AP mio] [N Gianni }]] \\
& \text { DEF my Gianni }
\end{aligned}
$$

\footnotetext{
${ }^{5}$ However, see Franks \& Pereltsvaig 2004 and Pereltsvaig 2006b on what looks like variable categorial features of nominal projections in Russian.
} 


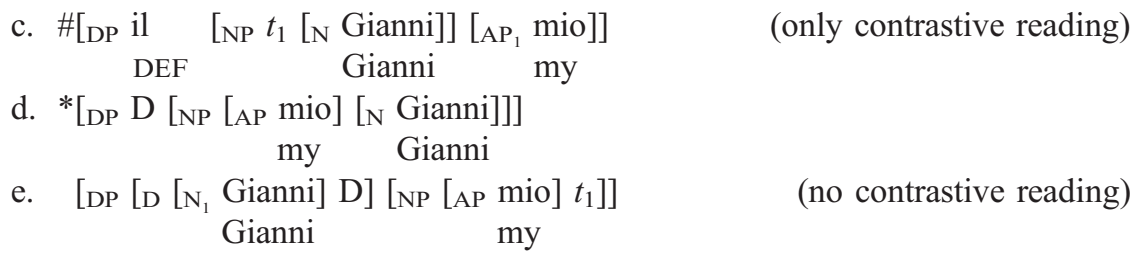

Adjectives (As) are merged between (overtly realized) D and N, never before D (see (3a)). An adjective is unmarked in its prenominal base position, but if $\mathrm{A}$ is in postnominal position it receives a contrastive interpretation. This is shown for the possessive adjective mio in $(3 \mathrm{~b}, \mathrm{c})$. Thus, $(3 \mathrm{c})$ implies a contrastive reading: There must be more than one Gianni provided by the context. Interestingly, when proper names appear without a determiner, we might a priori expect (3d), but this is impossible. Instead, the string $\mathrm{N}-\mathrm{A}$ in (3e) is well formed (and unmarked), which suggests that $\mathrm{A}$ is in its base position. Longobardi concludes that the base structure of (3e) must then be as in (3b,d), with $\mathrm{N}$ having undergone movement to $\mathrm{D}$ in (3e). The analysis accounts for the complementary distribution of $\mathrm{N}$ and $\mathrm{D}$ in the only position to the left of the adjective in the nominal projection; and it is far from obvious whether a convincing alternative analysis could be given of these facts that does not rely on $\mathrm{N}$ movement (given that mio has all the properties associated with in-situ prenominal adjectives in (3e)). ${ }^{6}$

More generally, we can conclude that movement of $\mathrm{N}$ in proper-name nominal projections in Italian is well motivated on the one hand, and incompatible with an analysis in which DP is merged in the specifier of N (an NP-over-DP analysis) on the other hand: The nominal projection has to be a projection of $\mathrm{D}$ (or of some other functional category).

\subsection{N Movement in Modern Hebrew}

Construct-state (CS) nominals in Modern Hebrew arise when the head noun is immediately followed by a genitive phrase. The linear order in CS nominals must be NSO, so the structure is head-initial. (Following Ritter 1988, O stands for "object" and S for "subject," where both describe structural positions: $\mathrm{S}$ is the specifier of $\mathrm{N}$,

\footnotetext{
${ }^{6}$ Despite its many virtues, it should not go unnoticed that Longobardi's analysis also faces several (albeit arguably minor) problems. First, if head movement is adjunction of one head to another (as is standardly assumed), $\mathrm{N}$ must be adjoined to an empty $\mathrm{D}$ in (3e). But then it is not evident why the usual (indefinite) interpretation of the empty D does not apply even in cases of $\mathrm{N}$ adjunction - the $\mathrm{D}$ head as such is still part of the structure. The problem does not arise if $\mathrm{N}$ is moved to $\mathrm{D}$ by substitution (rather than adjunction). But if $\mathrm{N}$ replaces $\mathrm{D}$ with all of its features, it should in fact become the head of the constituent and project an NP. Longobardi does not discuss these consequences, but the result of $\mathrm{N}$ movement via substitution would be quite similar in its consequences to the reprojection approach we propose in section 4-similar, but not quite identical, most obviously because movement via substitution is still at variance with the Extension Condition $\left(\mathrm{X}^{\prime}\right.$ must exist before substitution movement of $\mathrm{Y}^{0}$ out of the complement $\mathrm{YP}$ of $\mathrm{X}^{0}$ can take place to the $\mathrm{X}^{0}$ position) and other general principles (e.g., conditions of structure preservation).
} 
and $\mathrm{O}$ its complement.) In CS nominals, the definiteness marker $h a$ - shows up postnominally as a proclitic to the genitive phrase, but in non-CS nominals it appears in front of the head noun. Furthermore, definiteness spreading takes place in CS nominals: $h a$ - is realized in front of every item to the right of N. Relevant data are given in (4).

(4) a. beyt ha-mora

house DEF-teacher

'the house of the teacher'

b. ha-bayit

(non-CS)

DEF-house

'the house'

c. harisat ha-oyev 'et ha-'ir

destruction DEF-enemy OM DEF-city

'the enemy's destruction of the city'

d. beyt ha-mora ha-yafe

house DEF-teacher DEF-pretty

'the pretty house of the teacher'

Ritter (1988) postulates the following structures for CS nominals and non-CS nominals:

(5) a. [DPN (ha-) XP-GEN...]

b. [DP(ha-)N...]

Ritter's argument for N-to-D movement is as follows: First, the basic assumption is that CS nominals and non-CS nominals are to be derived from the same underlying structure (D-structure, in her case - governed by the principles of X-bar theory, and based on the assumption that heads precede complements). Second, SNO is assumed to be the base order. Third, this means that in CS nominals, $\mathrm{N}$ must move to the left; the only position that is available for such movement is D. Movement of $\mathrm{N}$ necessarily takes place via left-adjunction to D. By assumption, D then assigns abstract genitive case to the specifier of NP; and the definiteness marker $h a$ - cliticizes onto the following item (the genitive specifier); this latter movement, however, is not considered to be strictly syntactic (rather, it is viewed as a PF operation). The derivation of CS nominals in Modern Hebrew in Ritter's analysis is sketched in (6).

(6) $\left[\mathrm{DP}\left[\mathrm{DD}_{1} \mathrm{D}\right]\left[\mathrm{NP}\right.\right.$ DP-GEN $\left.\left.\left[\mathrm{N}^{\prime} t_{1} \mathrm{DP}\right]\right]\right]$

If this analysis is on the right track, it provides a strong prima facie argument against analyses in which DP acts as a specifier of NP (rather than as a projection above NP): 
There must be a position to which $\mathrm{N}$ can move in CS environments, so that it can end up in front of its genitive specifier. ${ }^{7}$

\section{$2.3 N$ Movement and Constraints on Word Order in Nominal Projections}

Cinque (2005) observes that out of the 24 possible orders of demonstrative (D), numeral ( $\mathrm{n}=$ Num), adjective $(\mathrm{A})$, and noun $(\mathrm{N})$ given in $(7)$, only the 14 orders in I are attested (as unmarked orders); the orders in II are not. (Here and in what follows, we abbreviate Number heads as n, not as Num. This should not be confused with "light" $\mathrm{n}$ as it was briefly discussed in the first section.)

\footnotetext{
(i) a. ha-harisa šel ha-oyev 'et ha-'ir DEF-destruction of DEF-enemy OM DEF-city 'the enemy's destruction of the city'

b. *ha-harisa 'et ha-'ir šel ha-oyev DEF-destruction OM DEF-city of DEF-enemy 'the enemy's destruction of the city'

c. ha-harisa šel ha-'ir al yedey ha-'oyev DEF-destruction of DEF-city by DEF-enemy 'the destruction of the city by the enemy'

(ii) a. ha-sefer šel ha-sifriya 'al ha-štixim DEF-book of DEF-library about DEF-rugs 'the library's book about rugs'

b. ha-sefer 'al ha-štixim šel ha-sifriya DEF-book about DEF-rugs of DEF-library 'the library's book about rugs'
}

7 That said, Ritter's analysis has not gone unchallenged; in particular, her premise concerning the uniform base order (i.e., SNO) may not be fully unproblematic. As a case in point, Borer (1999) presents an alternative analysis of CS nominals in Modern Hebrew; she shows that the word-order facts can be derived without movement of $\mathrm{N}$ to $\mathrm{D}$. For concreteness, Borer argues that there is a crucial difference between CS nominals with deverbal process nominals and CS nominals with nonderived nominals. In the former case, there is syntactic nominalization of a verb embedded under $\mathrm{N}$ that is accomplished by $\mathrm{V}$-to- $\mathrm{N}$ movement; in this construction, word order is fixed (except for active/passive alternations); see (i). In the latter case, there is free word order, with NOS as the base order (where $\mathrm{S}$ is right-adjoined to [NP N O], yielding [NP [NP N O] $\mathrm{S}]$ ); on this view, NSO is derived by subsequent right-adjunction of $\mathrm{O}$ : [NP [NP $\left.\left.\mathrm{N} \mathrm{t}_{\mathrm{O}}\right] \mathrm{S}\right] \mathrm{O}$; ; see (ii).

If this approach is adopted, there is no argument for the DP hypothesis based on $\mathrm{N}$ movement because the word order can be derived without such movement: In (i), $\mathrm{V}$ moves to a nominalizating $\mathrm{N}$ head, and in (ii) both orders are derived by right-adjunction of nominal projections. Similarly, Shlonsky (2004) argues against head movement in Hebrew (and Arabic) nominal projections. He suggests an approach that relies exclusively on XP movement (via remnant movement and massive pied piping); but see Pereltsvaig 2006a for arguments against this (and for a head movement approach). More generally, the analysis of CS nominals is widely disputed in the literature, and we cannot attempt to do the phenomenon justice here. Still, it may be noted that the kinds of right-adjunctions that Borer assumes are considered dubious in many theories of projection; and that a combination of massive pied piping and remnant movement as a replacement for head movement raises a number of open questions that, in our view, have not yet been comprehensively addressed (despite the important theoretical groundwork in Koopman \& Szabolcsi 2000), independently of potential empirical shortcomings as they are pointed out by Pereltsvaig (2006a). Therefore, at least for the sake of the argument, we will continue to assume that CS nominals in Modern Hebrew do provide direct word-order evidence for $\mathrm{N}$ movement. 
(7) Possible and impossible orders in nominal projections

\begin{tabular}{|c||cccc|}
\hline Ia & D & n & A & N \\
& D & n & N & A \\
& D & A & N & n \\
& D & N & A & n \\
& N & A & n & D \\
& A & N & n & D \\
& n & A & N & D \\
& n & N & A & D \\
\hline
\end{tabular}

\begin{tabular}{|c||cccc|}
\hline Ib & D & N & n & A \\
& N & n & A & D \\
& N & D & n & A \\
& N & D & A & n \\
& N & A & D & n \\
& A & N & D & n \\
\hline
\end{tabular}

\begin{tabular}{||c||ccccc|}
\hline $\mathrm{II}$ & $*$ & $\mathrm{D}$ & $\mathrm{A}$ & $\mathrm{n}$ & $\mathrm{N}$ \\
& $*$ & $\mathrm{~A}$ & $\mathrm{D}$ & $\mathrm{n}$ & $\mathrm{N}$ \\
& $*$ & $\mathrm{n}$ & $\mathrm{A}$ & $\mathrm{D}$ & $\mathrm{N}$ \\
& $*$ & $\mathrm{~A}$ & $\mathrm{n}$ & $\mathrm{D}$ & $\mathrm{N}$ \\
& $*$ & $\mathrm{~A}$ & $\mathrm{D}$ & $\mathrm{N}$ & $\mathrm{n}$ \\
& $*$ & $\mathrm{n}$ & $\mathrm{D}$ & $\mathrm{A}$ & $\mathrm{N}$ \\
& $*$ & $\mathrm{n}$ & $\mathrm{D}$ & $\mathrm{N}$ & $\mathrm{A}$ \\
& $*$ & $\mathrm{~A}$ & $\mathrm{n}$ & $\mathrm{N}$ & $\mathrm{D}$ \\
& $*$ & $\mathrm{n}$ & $\mathrm{N}$ & $\mathrm{D}$ & $\mathrm{A}$ \\
& $*$ & $\mathrm{~N}$ & $\mathrm{n}$ & $\mathrm{D}$ & $\mathrm{A}$ \\
\hline
\end{tabular}

For now, the difference between the orders in Ia and the orders in Ib orders can be ignored; it will become relevant later. An example from English instantiating one of the 14 legitimate orders is given here.

(8) these seven white mice

D $n \quad$ A $\mathrm{N}$

In the following two subsections we briefly outline two analyses that derive the patterns. $^{8}$

\subsubsection{Cinque's (2005) analysis}

Cinque makes five assumptions concerning base structure and constraints on movement to derive the possible orders and to exclude the impossible ones. First, he invokes the Linear Correspondence Axiom (LCA; see Kayne 1994), according to which each phrase has the structure in (9). (Strictly speaking, it follows from the LCA that YP must be a unique adjunct, and $\mathrm{X}^{\prime}$ is XP. We ignore this complication here.)

(9) $\left[\mathrm{xP}(\mathrm{YP})\left[\mathrm{x}^{\prime} \mathrm{X}(\mathrm{ZP})\right]\right]$

Heads always precede their complements and follow their specifiers; specifiers must be unique (thus, there are no multiple specifiers). Furthermore, the following hierarchy of the elements in their base position is postulated: $\mathrm{D} \succ \mathrm{n} \succ \mathrm{A} \succ \mathrm{N}$, where $\succ$ stands for c-command. As a consequence, only this order can be base-generated and the other 13 possibilities are derived by movement. By assumption, head

\footnotetext{
${ }^{8}$ Throughout this paper, we will not be overly concerned with potential counterexamples to these generalizations (but see section 4.4); these are tackled in the two articles on which our analysis is based. As before, our main concern is not so much the empirical correctness of every minute detail; recall that we are mainly interested in reanalyzing arguments for movement in nominal projections in an approach that does not envisage DP (-like) structure above NP. To this end, the arguments for movement must be assumed to be basically valid.
} 
movement is excluded; all movement is phrasal. Movement must always go to the left (because of the LCA). Thus, movement targets specifier positions of additional functional heads in the nominal projection. In addition to these general assumptions, Cinque (2005) makes a number of more specific assumptions about possible and impossible movement operations in nominal constructions. First, movement may apply totally to an XP that is the specifier of the highest functional category in the nominal projection, or it applies partially to a specifier of a functional category below the highest one. Second (and this will be of particular importance in the context of the analysis we propose in section 4), movement can only involve a subtree containing $\mathrm{N}$. There are further restrictions on what such a subtree can look like. It may contain $\mathrm{N}$ and no other lexical item. Alternatively, it may involve pied-piping of further material by N. Such pied-piping comes in two varieties: In one, $\mathrm{N}$ stays in its base position and the constituent immediately containing $\mathrm{N}$ and its sister is moved (the whose picture type); in the other, $\mathrm{N}$ first moves alone and pied-pipes its sister node in a second movement step (the picture of who type). The basic structure of nominal projections presupposed by Cinque's (2005) approach involves a number of additional functional projections (abstract agreement projections and projections providing specifiers for items like DP, nP, and AP to be merged in, here labeled WP, XP, and YP). It is given in (10).

$$
\begin{aligned}
& {\left[\operatorname{Agr}_{\mathrm{w}} \mathrm{P}-\left[\mathrm { Agr } _ { \mathrm { w } } { } ^ { \prime } \operatorname { A g r } _ { \mathrm { w } } \left[\mathrm { WP } \mathrm { DP } \left[\mathrm { w } ^ { \prime } \left[\mathrm { w } \left[\operatorname{Agr}_{\mathrm{x}} \mathrm{P}-\left[\operatorname { A g r } _ { \mathrm { x } } { } ^ { \prime } \operatorname { A g r } _ { \mathrm { x } } \left[\mathrm { XP } \mathrm { nP } \left[\mathrm { x } ^ { \prime } \mathrm { X } \left[\operatorname{Agr}_{\mathrm{y}} \mathrm{P}-\right.\right.\right.\right.\right.\right.\right.\right.\right.\right.} \\
& \left.\left.\left.\left.\left.\left.\left.\left.\left.\left[\operatorname{Agr}_{\mathrm{y}}{ }^{\prime} \operatorname{Agr}_{\mathrm{y}}\left[\mathrm{YP} \operatorname{AP}\left[\mathrm{y}^{\prime} \mathrm{NP}\right]\right]\right]\right]\right]\right]\right]\right]\right]\right]\right]\right]
\end{aligned}
$$

Consider a few examples. The order $\mathrm{N}-\mathrm{D}-\mathrm{n}-\mathrm{A}$ can be derived by totally moving (a constituent containing) $\mathrm{N}$ alone successive-cyclically through each specifier. $\mathrm{D}-\mathrm{A}-\mathrm{N}-\mathrm{n}$ is the result of partially moving (a constituent containing) $\mathrm{N}$ and $\mathrm{A}$ (the whose picture type) to Spec, $\operatorname{Agr}_{\mathrm{X}}$. Movement of (a constituent containing only) $\mathrm{N}$ to Spec, $\operatorname{Agr}_{Y}$ followed by movement of $\operatorname{Agr}_{Y P}$ (picture of who type) to $\mathrm{SpecAgr}_{\mathrm{X}}$ results in $\mathrm{D}-\mathrm{N}-\mathrm{A}-\mathrm{n}$. This way, all the established orders can be generated. However, if only one of the assumptions mentioned above were to be abandoned (e.g., the restriction that only subtrees containing $\mathrm{N}$ can be moved), unattested word orders would be predicted to arise. For instance, if AP could undergo movement alone, landing in, say, Spec, Agr ${ }_{\mathrm{W}}$, the unattested word order *A-D-N-n would arise; or if $\mathrm{nP}$ could undergo movement alone, e.g., to $\mathrm{Spec}, \mathrm{Agr}_{\mathrm{W}}$, the unattested word order $*_{\mathrm{n}}-\mathrm{D}-\mathrm{A}-\mathrm{N}$ could come into existence.

\subsubsection{Abels \& Neeleman's (2006) reanalysis}

Abels \& Neeleman (2006) show that one can derive the patterns in (7) in a somewhat simpler way that shares some of Cinque's assumptions while abandoning others; in particular, the LCA is not adopted. Thus, Abels \& Neeleman keep the assumption that the underlying hierarchical order of elements is $\mathrm{D} \succ \mathrm{n} \succ \mathrm{A} \succ \mathrm{N}$ for external Merge, but they abondon the LCA. Consequently, complements and specifiers may be generated to the left or to the right of a head, regulated by language-specific 
parameterization. Therefore, the orders in Ia in (7) can all be base-generated. In contrast, the orders in Ib in (7) are derived by movement. As before, there are a number of constraints on movement: General restrictions on movement imply that it must go to the left, and that it always ends in a c-commanding position. Interestingly, as in Cinque's (2005) approach, a specific assumption for movement in nominal projections is required: By stipulation, only those subtrees can undergo movement in nominal projections that contain N. These assumptions suffice to exclude the orders in II in (7). And again, each of these assumptions is necessary to achieve this result. If, for instance, movement of a constituent that does not contain $\mathrm{N}$ is permitted, or if the hierarchy of projections is not strict, unattested orders arise, exactly as with Cinque's (2005) analysis.

Some possible movements do not lead to new orders. For example, D-N-A-n may be base-generated with $\mathrm{A}$ and $\mathrm{n}$ to the right of $\mathrm{N}$, and $\mathrm{D}$ to its left, but it may also be the result of moving the subtree $\mathrm{N}$ out of the basic order $\mathrm{D}-\mathrm{A}-\mathrm{N}-\mathrm{n}$. Both possibilities are shown in (11). ${ }^{9}$
(11) a. $[\mathrm{D}[[\mathrm{N} \mathrm{A}] \mathrm{n}]]$
b. $\left[\mathrm{D}\left[\mathrm{N}\left[\left[\begin{array}{ll}\mathrm{A} & \left.\left.\left.\left.\mathrm{t}_{\mathrm{N}}\right] \mathrm{n}\right]\right]\right]\end{array}\right]\right.\right.\right.$

Cinque (2005) assumes a single strict basic linearization of D, n, A and N but allows various types of movement. In contrast, Abels \& Neeleman (2006) permit more word orders to be base-generated (by abandoning the LCA) and constrain movement more strictly, thereby simplifying Cinque's system. ${ }^{10}$

Note that without the LCA, the lexical elements D, A, and $\mathrm{n}$ do not need to be introduced by functional heads anymore. Given the possibility of multiple specifiers they do not have to erect their own projection each-a point that will also be important in our analysis in section 4 . Nevertheless, in both analyses there remains the crucial but not independently motivated assumption that only a subtree containing $\mathrm{N}$ can move. We will show that this follows automatically in an analysis that relies on reprojection of $\mathrm{N}$.

\section{Reprojection}

\subsection{Background}

Surányi (2005) argues that assuming reprojection of heads (or "root merger") instead of head movement as adjunction solves a range of problems associated with the latter concept. An adjoined head behaves differently from moved phrases in several respects, which gives rise to various problems. Among these problems are the following: An

\footnotetext{
${ }^{9}$ Abels \& Neeleman do not label nonterminal nodes in their trees, because, as they point out, the labels do not have any impact on the point they want to make. Therefore, it is not clear whether the moved element adjoins to or substitutes for a functional head, or neither. We will return to this question and to the question of labeling the nonterminal nodes in our reanalysis in section 4.

${ }^{10}$ As shown by Abels \& Neeleman (2006), a formal proof can be given that the two approaches are empirically equivalent: Translation rules can transform Cinque's approach into Abels \& Neeleman's, and vice versa.
} 
adjoined head does not c-command its base position (cf. Brody 2003, Mahajan 2003, Matushansky 2006) unless the definition of c-command is complicated (as, e.g., in Baker 1988); it does not extend the tree at its root as demanded by the Extension Condition (Chomsky 1995); and it cannot apply successive-cyclically because the Head Movement Constraint (see Travis 1984) excludes excorporation of a head (but also cf. Roberts 1991, 2001 for possible qualifications). If, however, head movement is interpreted in terms of movement and reprojection, these problems do not arise. Reprojection means that a head is moved out of its projection and takes it as its own complement by merging with it, projecting anew in the derived position; see (12).

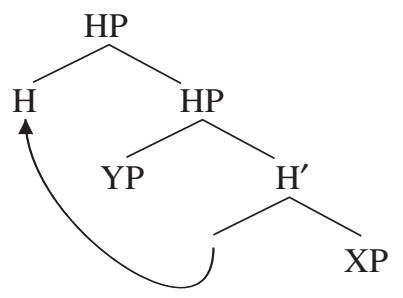

Here, the remerged head c-commands its base posititon; the movement operation extends the tree generated so far; and the operation may be applied recursively.

An analysis that makes uses of reprojection (-like operations) is developed by Haider $(2000,2005,2006)$. Haider is concerned with the question of how phrase structure is generated in SVO systems, where there is asymmetric c-command (from left to right) of items that are attached to the main projection line. His analysis relies on a specific version of a Larsonian VP shell approach (Larson 1988). More specifically, Haider argues that VP shells are not introduced by designated (and semantically nonempty) functional categories, such as CAUS-v, VOICE-v, or APPL-v (see, e.g., Harley 1995, Kratzer 1996, Adger 2003, Ramchand 2003, Schäfer 2007, and references cited in the latter three works). Rather, VP shells arise for purely formal reasons, due to the necessity of discharging subcategorization features of $\mathrm{V}$ - by assumption, such a feature discharge is not possible in English (or SVO systems more generally) by creating right-peripheral specifiers. Haider derives this from his Branching Conjecture, which demands that for any two nodes that are directly attached to the same projection line, the preceding node must c-command the node that follows. Hence, to derive the linearization of an English-type system, V must raise out of its base position and thereby create a VP shell, so that it can end up in a position to the left of its argument, which would otherwise precede the verb. In essence, then, this analysis relies on reprojection. ${ }^{11}$ In what follows, we essentially adopt Haider's subcategorization-based motivation for reprojection movement. However, our approach dispenses with the Branching Conjecture and derives reprojection by invoking a special type of probe feature that may accompany a

\footnotetext{
${ }^{11}$ Haider (2006) does not address the issue in exactly these terms, though, because he envisages a representational system in which head movement by reprojection is modeled in terms of multimembered head chains.
} 
subcategorization feature and that may trigger movement of a head in order to be checked under c-command. We call these features Münchausen features. ${ }^{12}$ The system is outlined in detail in the next two sections.

\subsection{Architecture of the System}

We presuppose a version of derivational syntax according to which all syntactic operations are triggered by features; in particular, we assume that features trigger both Agree operations and structure-building operations (internal and external Merge). ${ }^{13}$ Thus, suppose that external Merge is triggered by subcategorization features and that internal Merge (movement) is triggered by movement-type specific specifier features. These two kinds of features can be subsumed under one type: structure-building features. We render structure-building features in a $[\bullet \mathrm{F} \bullet]$ notation. We further assume that linking is brought about by mapping hierarchies of $\theta$-roles onto hierarchies of subcategorization features on a predicate in reverse order; thus, subcategorization features show up on stacks (and only the topmost item is accessible at any given point, as with pushdown automata; see below). ${ }^{14}$ On this view, multiple specifiers come into existence by successively discharging structure-building features of a lexical item. To ensure that all instances of subcategorization-driven structurebuilding precede all instances of movement (in the domain of a given lexical item),

\footnotetext{
${ }^{12}$ Baron Münchhausen is both a historical and a literary character. He shows up in various German tall tales; in one of them, he escapes from a swamp (where he is trapped on the back of his horse) by pulling himself up by his own hair. As far as we can tell, the use of the name "Münchhausen" in syntactic theory goes back to Sternefeld's (1991) characterization of an operation employed in Chomsky's (1986) theory of barriers: Here, VP is a barrier, but a V moved to I can belatedly justify its own (originally impossible) movement across the VP barrier by L-marking VP and removing barrierhood-clearly a case of pulling oneself up by one's own hair. Fanselow (2003) applies the concept to reprojection movement ("Münchhausen-style head movement"); we follow him in this respect (although his approach otherwise bears little resemblance to ours).

${ }^{13}$ The basic system is laid out in more detail in Heck \& Müller 2007 and Müller 2007, and further motivation for the features and operations involved is provided there. For the assumption that all structurebuilding operations (including external Merge) are triggered by features, see, among others, Svenonius 1994; Stabler 1996, 1997, 1998; Collins 2003; Adger 2003; Heck \& Müller 2007, Kobele 2006, Sternefeld 2006, Lahne 2006; and Pesetsky \& Torrego 2006. This view is not compatible with Chomsky 2007, though.

${ }^{14}$ Such an approach has a long tradition going back to categorial grammar; see, for example, Lewis 1972. Also cf. Pollard \& Sag 1994, Wunderlich 1997, and Lechner 2004, among many others, for implementations in different theoretical frameworks. A reviewer raises the issue of whether evidence from adverb placement could not threaten to undermine such an approach to argument projection: As argued by Bobaljik (1999), there is a hierarchy of arguments, and there is an independent hierarchy of adverbs, and the two can be combined in various ways, "like two decks of cards," in the reviewer's terms. Assuming this to be correct, such an interleaving of hierarchies may at first sight look problematic for the present approach because it is not obvious how the encodings for the two types of structure-building could be represented on a single head. However, on the one hand, it may turn out that these problems are pureley technical and can be overcome in a relatively simple way (for instance, by defining an operation on lexical entries in the lexicon or in the numeration that selectively, and hierarchy-preservingly, intersperses features for adjuncts into stacks of structure-building features). On the other hand, given that adjuncts are standardly taken to enter syntactic derivations not by Merge, but by a different operation (Adjoin), the interleaving of the two hierarchies might best be viewed as resulting from the interaction of two different operations: Merge is hierarchy-preserving because structure-building features are part of a stack, and Adjoin is hierarchypreserving by definition (ultimately, the hierarchy of adjuncts may turn out to be a consequence of the different types of semantic interpretation given to different types of adjuncts).
} 
we assume that movement-inducing structure-building features always show up below subcategorization features in $[\bullet \mathrm{F} \bullet$ ] feature stacks of heads.

In addition to structure-building $([\bullet \mathrm{F} \bullet])$ features, there are probe features, as in Chomsky $(2000,2001)$. Probe features (which we note as $[* F *]$ ) must find a matching goal under Agree; the Agree operation in turn requires c-command. Since such a c-command requirement does not hold for structure-building features (almost by definition, since they must be able to create specifiers), there is an interesting asymmetry between $[\bullet \mathrm{F} \bullet]$ checking and $[* \mathrm{~F} *]$ checking; and it is this asymmetry that we will exploit in our approach to reprojection. For now, we may confine ourselves to assuming that probe features and structure-building (subcategorization or movementinducing) features are located on different feature stacks of lexical items (whether probe features are also ordered is irrelevant for what follows).

Next, we adopt the version of the Strict Cycle Condition (see Chomsky 1973, 1995) in (13). ${ }^{15}$

(13) Strict Cycle Condition

Only the head of the present root can have features that trigger operations $([\bullet \mathrm{F} \bullet]$ or $[* \mathrm{~F} *])$.

A Last Resort requirement ensures that all syntactic operations must be triggered by features and that only those (structure-building or probe) features are accessible at any given step that are located on top of a feature stack; see (14).

\section{Last Resort}

a. A syntactic operation must discharge (and delete) $[\bullet \mathrm{F} \bullet]$ or $[* \mathrm{~F} *]$.

b. Only $[\bullet \mathrm{F} \bullet]$ or $[* \mathrm{~F} *]$ features that are on top of a feature stack are accessible.

Given that there are two feature stacks (one for $[\bullet \mathrm{F} \bullet]$ features that trigger external or internal Merge, and one for $[* \mathrm{~F} *]$ features that trigger Agree), indeterminacies in rule application may arise. They are resolved in a principled way by the constraint in (15) (which is modeled on Chomsky's [1995] Merge over Move).

Agree over Merge

If both $[\bullet \mathrm{F} \bullet]$ and $[* \mathrm{~F} *]$ can be discharged, $[* \mathrm{~F} *]$ is given preference.

\footnotetext{
${ }^{15}$ Two remarks. First, note that the Strict Cycle Condition in (13) not only derives cyclicity of rule application (in interaction with Last Resort as defined below); it also ensures that all operation-inducing features must be checked (and discharged, i.e., deleted). Given the specific formulation in (13), the constraint is strictly speaking incompatible with the idea of feature valuation of probes. Indeed, throughout this paper, we presuppose a checking (rather than valuation) approach, but a minimal modification of (13) would make it compatible with valuation: Essentially, stripping away $*$ on probes would suffice. See Richards 2007 for discussion of some of the (mainly spell-out-related) issues that are involved here. Second, as it stands, (13) requires a start symbol $\mathrm{E}:\{[\bullet \mathrm{C} \bullet]\}$ to guarantee that there are no completed derivations with unchecked features (alternatively, the relevant derivations might be assumed to crash at an interface).
} 
Let us illustrate the basic structure-building system with an NP, adopting the NP-overDP hypothesis. ${ }^{16}$ Consider the derivation in (16).
a. $\mathrm{N}:\{[\bullet \mathrm{A} \bullet] \succ[\bullet \bullet \bullet] \succ[\bullet \mathrm{D} \bullet]\}$
(initial features on $\mathrm{N}$; lexicon)
b. $\mathrm{N}:\{[\bullet \mathrm{A} \bullet] \succ[\bullet \mathrm{D} \bullet]\}$
(optional deletion; numeration)
c. $\operatorname{Merge}(\mathrm{N}:\{[\bullet \mathrm{A} \bullet] \succ[\bullet \mathrm{D} \bullet]\}, \mathrm{AP}) \Rightarrow\left[\mathrm{N}^{\prime} \mathrm{AP} \mathrm{N}:\{[\bullet \mathrm{D} \bullet]\}\right]$
d. Merge $\left(\left[\mathrm{N}^{\prime}\right.\right.$ AP N: $\left.\left.\{[\bullet \mathrm{D} \bullet]\}\right], \mathrm{DP}\right) \Rightarrow\left[{ }_{\mathrm{NP}} \mathrm{DP}\left[\mathrm{N}^{\prime}\right.\right.$ AP N: $\left.\left.\{-\}\right]\right]$
e. Merge $(\mathrm{X}:\{[\bullet \mathrm{N} \bullet] \succ \ldots\}, \mathrm{NP}) \quad \Rightarrow\left[\mathrm{X}^{\prime} \mathrm{X}:\{\ldots\} \mathrm{NP}\right]$
etc.

Thus, suppose that a phrase is to be generated in which the head $\mathrm{N}$ takes a prenominal adjective and a demonstrative. According to the feature hierarchy on $\mathrm{N}$ in (16a), the subcategorization features for $\mathrm{A}$ and $\mathrm{D}$ are ordered on $\mathrm{N}$ in the numeration as in (16b). Consequently, $[\bullet A \bullet]$ has to be discharged before $[\bullet \mathrm{D} \bullet]$ is discharged. This is shown in (16c), where AP merges with $N$, yielding $\mathrm{N}^{\prime}$; and in (16d), where DP is merged with $\mathrm{N}^{\prime}$ (triggered by N's remaining subcategorization feature), which yields NP (the constituent qualifies as a full XP if we assume that a projection is an XP iff its head does not have any structure-building or probe features). Finally, this NP may then undergo Merge with some other head, triggered by a structure-building feature of that head (see (16e)).

So far, nothing is said about linearization. We make the standard assumption that Merge operations are independent of linear order. The linearization of complements and specifiers is regulated by language-specific (and also category-specific) linearization rules that affect the tree directly after each Merge operation.

Against this background (which we take to be fairly standard, no more than one of the several possibilities to implement structure-building and Agree operations in a derivational syntax based on certain minimalist assumptions), we can now turn to the role of Münchhausen features in inducing reprojection.

\subsection{Münchhausen Features}

A Münchhausen feature is nothing special: It is simply a probe feature with a category label as its content that accompanies a structure-building feature with the same category label; this way, it brings about a special identification of subcategorized items. Thus, if a feature $[\bullet \mathrm{F} \bullet]$ on a lexical item co-occurs with a corresponding feature $[* \mathrm{~F} *]$, the latter is a Münchhausen feature. Agree over Merge demands that probe features are checked before structure-building features where possible, but of course, discharge of $[* \mathrm{~F} *]$ (with $\mathrm{F}$ a category label) requires the presence of a category labeled $\mathrm{F}$ in the c-command domain of the head to be applicable. Two cases can be distinguished. First, $[\bullet \mathrm{F} \bullet]$ may be topmost on the initial stack, in which case it

\footnotetext{
${ }^{16} \mathrm{~N}$ differs from $\mathrm{V}$ in that all subcategorization of arguments is optional; similarly, AP modifiers are optional; and (notwithstanding Longobardi's analysis of Italian) perhaps DP subcategorization is not entirely general, either, but may be suppressed in certain environments or in certain languages. For concreteness, we assume that optional subcategorization is captured by optionally deleting structurebuilding features when an item has entered the numeration; this operation applies freely with $\mathrm{N}$, and is severely restricted with V. Of course, many other approaches are possible.
} 
creates a complement with label $\mathrm{F}$. In this case, $[* \mathrm{~F} *]$ can (and, given Agree over Merge: must) be discharged immediately afterward, which creates no discernible effect. Alternatively, $[\bullet \mathrm{F} \bullet]$ may not be topmost on an initial stack on a lexical item; that is, it generates a specifier. In that case, the probe feature $[* \mathrm{~F} *]$ accompanying it has an interesting effect. Being a probe feature, it must be checked under c-command. However, a head does not c-command its specifier. Therefore, the Münchhausen feature cannot be checked with a specifier if the head stays in situ. ${ }^{17}$

There is one way out of this dilemma: The lexical item bearing the Münchhausen probe feature that cannot be discharged with the specifier moves out of its projection and remerges with it, projecting anew. After this movement step, Agree becomes possible because the probe feature on the moved head c-commands the specifier of the projection of which it was originally the head. Because the head bearing at least one operation-inducing feature (namely, the Münchhausen feature - possibly there are still others left on it) has been moved out of its projection, this projection qualifies as an XP in the sense of the Strict Cycle Condition (see (13)): As soon as the head moves out, there are no probe or structure-building features left in its original projection. ${ }^{18}$ All this is shown schematically in (17), where the moved head $X$ reprojects an $X^{\prime}$ category and discharges its probe feature with the specifier of its original projection-note that $\mathrm{X}$ still has a structure-building feature in this derivation which will yield a ZP specifier in the derived projection in a subsequent step that is not depicted here.
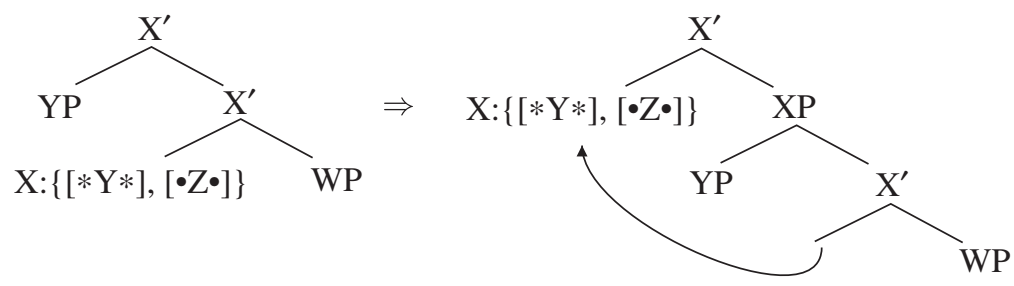

17 This reasoning presupposes that operation-inducing features are not projected from a lexical item $\mathrm{X}$ to its $\mathrm{X}^{\prime}$ projections - otherwise, $\mathrm{X}^{\prime}$ could discharge a probe feature by Agree with a specifier. Indeed, it seems to us that such a feature projection should be rejected on conceptual grounds if possible: Either, an additional projection mechanism must be postulated that shares certain properties with movement, or the problem will arise that (unchecked) operation-inducing features are duplicated with each structure-building operation (and should therefore trigger many more operations than desired) - something that is unproblematic with features that do not trigger operations, like, e.g., the category label. (That said, nothing in what follows is incompatible with the idea that category labels are not projected, either. See Collins 2003 for relevant discussion.) However, it should be noted that we will eventually invoke a projection of certain probe (not structure-building) features in section 4 (for one specific purpose: pied-piping).

18 The assumption that the base position of movement is inert in this sense is unavoidable if countercyclic operations (e.g., checking of identical features in the landing site and in the base position) are to be avoided. There are various ways to derive this. One is to assume that movement leaves traces $(t)$, and traces lack operation-inducing features by definition. Another is to assume that movement leaves copies; in that case, something extra needs to be (and can be) said so as to ensure that feature discharge may not accidentally leave unchecked features on the lower copy (see Nunes 2004). A third possibility relies on the idea that movement gives rise to multidominance configurations (see Gärtner 2002, among many others); this option would seem to be incompatible with the present approach unless further assumptions are made. Finally, inertness of the base position of movement follows straightforwardly if movement does not leave anything behind - neither traces nor copies (see, e.g., Epstein et al. 1998, Müller 1998). For the sake of concreteness, we will adopt the last option in what follows; but nothing really depends on this choice. 
The lexical head $\mathrm{X}$ must move immediately if it is possible to check its feature [*F*] afterwards, because probe features have to be deleted before subcategorization features (the Agree over Merge constraint; see (15)). Reprojection movement is not directly feature-driven and therefore violates Last Resort (see (14)); it is legitimated by feature checking of $[* \mathrm{Y} *]$, which becomes possible only after its application. Thus, we conclude that Last Resort must be minimally violable in favor of the Strict Cycle Condition in (13) (which implies that operation-inducing features must be discharged, among other things). This in effect amounts to an optimization procedure in syntax (see Prince \& Smolensky 2004), albeit of a fairly local type. More specifically, the local domain that serves as the domain for optimization cannot be the derivational step (as assumed in Heck \& Müller 2007); rather, it must be something that is a little bigger - either the completed phrase (see Heck \& Müller 2003), or at least the completed projection (i.e., the result of a structure-building operation, together with all Agree operations carried out in the new structure). For concreteness, we assume the latter (and this is also the domain in which Agree over Merge holds). The reason is that the present system requires minimal look-ahead: Movement of a lexical item bearing a Münchhausen feature (which cannot be checked when the lexical item is in situ, because of a failure of c-command) violates Last Resort, but this Last Resort violation is possible if the Münchhausen feature can be discharged in the next step, as a consequence of the movement. ${ }^{19}$

\footnotetext{
${ }^{19}$ Closer inspection reveals that such a minimal look-ahead may in fact not be specific to Münchhausen feature-driven movement but may emerge as a property of all instances of feature-driven structure-building that involve a matching of two pieces of information. Thus, (external and internal) Merge triggered by [• $\bullet \bullet$ ] features can also be viewed as comprising two separate steps: first, the structure-building operation, and second, checking of $[\bullet \mathrm{F} \bullet]$ with an appropriate feature $\mathrm{F}$ on some XP (the category label with external Merge, typically a noncategorial feature with internal Merge). On this view, the only relevant difference between feature-driven Merge and Münchhausen movement is that we are dealing with a probe feature in the latter case - and probe features can also be checked without an additional structure-building operation having taken place, which $[\bullet \mathrm{F} \bullet]$ cannot. The conclusion that feature-driven Merge may imply minimal look-ahead holds more generally, and independently of specific assumptions about the make-up of featuredriven structure-building (e.g., $[\bullet \mathrm{F} \bullet]$ features), unless one adopts the radical view that no instance of structure-building involves matching features on the two categories that participate in the operation. That said, a viable alternative to assuming violability of Last Resort (in favor of the requirement that probe features must be checked) would consist in reformulating Last Resort in such a way that minimal lookahead is permitted (say, by replacing "must discharge" by "must result in discharge in a subsequent - essentially: the next but one-movement step"). Such a version of Last Resort is in fact adopted by Surányi (2005), in the context of his discussion of reprojection movement. A version of this latter approach would be to assume that the two operations in question (i.e., structure-building plus matching of features) effectively count as one composite operation, in all cases (i.e., whether they involve $[\bullet \mathrm{F} \bullet]$ or $[* \mathrm{~F} *]$ (Münchhausen) features). The various options instantiate a well-known trade-off between simplicity of concepts (the optimality-theoretic perspective) and avoidance of ranking (the non-optimalitytheoretic perspective). This issue is orthogonal to our main concerns here. Finally, it should be kept in mind that the look-ahead issue discussed here has little to do with standard cases of global look-ahead in syntax, where, for example, the legitimacy of some operation can only be determined at the very end of the derivation (or, for that matter, at the next phase level).
} 


\subsection{Reprojection within VP}

With the basic system of reprojection movement in place, let us return to Haider's (2006) analysis of VPs in SVO languages and see how it can be implemented in the present analysis. Consider a ditransitive English VP such as (18).

(18) Mary gave it to John.

Suppose that what characterizes SVO systems like the English one is that all subcategorization features of $\mathrm{V}$ are invariably accompanied by corresponding Münchhausen probe features demanding Agree operations with the subcategorized arguments; that is, requiring special argument identification. ${ }^{20}$ The derivation of (18) then looks like (19). By assumption, there is a categorial probe feature for each subcategorization feature on V (see (19a)); and there are three such subcategorization features for the ditransitive verb give that are derived by reversing the order of $\theta$-roles. ${ }^{21}[\bullet P \bullet]$ (which corresponds to the $\theta$-role GOAL in V's $\theta$-grid) is topmost on the subcategorization feature stack, so it is discharged first, making PP V's complement; see (19b). After this, the PP argument is (vacuously) identified by the categorial probe feature $[* \mathrm{P} *]$, under c-command (see (19c)). In the next step, the THEME $\mathrm{NP}_{2}$ is merged and becomes a specifier (see (19d)); however, this time the Münchhausen feature [*N*] on V cannot be discharged immediately because $\mathrm{NP}_{2}$ is not c-commanded by $\mathrm{V}$ in situ. Consequently, $\mathrm{V}$ movement and reprojection apply (as in (19e)), and $\mathrm{NP}_{2}$ in the specifier position can be identified by $[* \mathrm{~N} *]$ discharge in the next step (cf. (19f)). In the final three steps, the pattern is repeated: The remaining subcategorization feature $[\bullet \mathrm{N} \bullet$ ] (which encodes the AGENT $\theta$-role) is discharged, creating an $\mathrm{NP}_{1}$ specifier that the $\mathrm{V}$ head cannot agree with (see $(19 \mathrm{~g})$ ); movement and reprojection apply (see (19h)); and finally, the external argument $\mathrm{NP}_{1}$ is identified by Agree involving $[* \mathrm{~N} *]$ and the argument's category label (see (19i)).

\footnotetext{
${ }^{20}$ This leaves open the possibility that Münchhausen features could also be involved in the generation of VP shells in SOV languages (which, e.g., might underlie the different behavior of preverbal argument NPs in German and Dutch with respect to issues like scrambling and anaphoric binding). Additionally, nothing so far excludes systems with right-peripheral specifiers that asymmetrically c-command complements (and other specifiers merged earlier). We take this consequence to be empirically supported.

${ }^{21}$ External arguments are subcategorized by $\mathrm{V}$ on this view. However, nothing we have to say here would be radically changed if we were to assume that external arguments are not subcategorized by $\mathrm{V}$ but introduced by a designated functional category.
} 
(19) a. V's feature set: $\{[\bullet \mathrm{P} \bullet] \succ[\bullet \mathrm{N} \bullet] \succ[\bullet \mathrm{N} \bullet],[* \mathrm{P} *],[* \mathrm{~N} *],[* \mathrm{~N} *]\}$

(gave)

b. Merge $(\mathrm{V}:\{[\bullet \mathrm{P} \bullet] \succ[\bullet \mathrm{N} \bullet] \succ[\bullet \mathrm{N} \bullet]\}, \mathrm{PP}) \Rightarrow\left[\mathrm{V}^{\prime} \mathrm{V}:\{[\bullet \mathrm{N} \bullet] \succ[\bullet \mathrm{N} \bullet]\right.$, $[* \mathrm{P} *],[* \mathrm{~N} *],[* \mathrm{~N} *]\} \mathrm{PP}]$

(gave to John)

c. $\left.\operatorname{Agree}([* \mathrm{P} *], \mathrm{PP}) \Rightarrow\left[\mathrm{V}^{\prime} \mathrm{V}:\{\bullet \mathrm{N} \bullet] \succ[\bullet \mathrm{N} \bullet],[* \mathrm{~N} *],[* \mathrm{~N} *]\right\} \mathrm{PP}\right]$

d. $\operatorname{Merge}\left(\left[\mathrm{V}^{\prime} \mathrm{V}:\{[\bullet \mathrm{N} \bullet] \succ[\bullet \mathrm{N} \bullet],[* \mathrm{~N} *],[* \mathrm{~N} *]\} \mathrm{PP}\right], \mathrm{NP}_{2}\right) \Rightarrow$ $\left[\mathrm{V}^{\prime} \mathrm{NP}_{2}\left[\mathrm{v}^{\prime} \mathrm{V}:\{[\bullet \mathrm{N} \bullet],[* \mathrm{~N} *],[* \mathrm{~N} *]\} \mathrm{PP}\right]\right]$

(it gave to John)

e. $\operatorname{Move}\left(\mathrm{V}:\{[\bullet \mathrm{N} \bullet],[* \mathrm{~N} *],[* \mathrm{~N} *]\}\left[\mathrm{vP}_{2} \mathrm{NP}_{2}\left[\mathrm{v}^{\prime} \mathrm{V} \mathrm{PP}\right]\right]\right) \Rightarrow$ $\left[\mathrm{V}^{\prime} \mathrm{V}:\{[\bullet \mathrm{N} \bullet],[* \mathrm{~N} *],[* \mathrm{~N} *]\}\left[\mathrm{VP} \mathrm{NP}_{2}\left[\mathrm{~V}^{\prime}-\mathrm{PP}\right]\right]\right.$ (gave it to John)

f. Agree $\left([* \mathrm{~N} *], \mathrm{NP}_{2}\right) \Rightarrow\left[\mathrm{v}^{\prime} \mathrm{V}:\{[\bullet \mathrm{N} \bullet],[* \mathrm{~N} *]\}\left[\mathrm{vP} \mathrm{NP}_{2}\left[\mathrm{v}^{\prime}-\mathrm{PP}\right]\right]\right.$

g. $\operatorname{Merge}\left(\left[\mathrm{v}^{\prime} \mathrm{V}:\{[\bullet \mathrm{N} \bullet],[* \mathrm{~N} *]\}\left[\mathrm{vP} \mathrm{NP}_{2}\left[\mathrm{v}^{\prime}-\mathrm{PP}\right]\right]\right], \mathrm{NP}_{1}\right) \Rightarrow$ $\left[\mathrm{V}^{\prime} \mathrm{NP}_{1}\left[\mathrm{v}^{\prime} \mathrm{V}\left[\mathrm{vP} \mathrm{NP}_{2}\left[\mathrm{v}^{\prime}-\mathrm{PP}\right]\right]\right]\right] \quad$ (Mary gave it to John)

h. $\operatorname{Move}\left(\mathrm{V}:\{[* \mathrm{~N} *]\},\left[\mathrm{vP} \mathrm{NP}_{1}\left[\mathrm{v}^{\prime} \mathrm{V}\left[\mathrm{vP} \mathrm{NP}_{2}\left[\mathrm{v}^{\prime}-\mathrm{PP}\right]\right]\right]\right) \Rightarrow\right.$ $\left[\mathrm{v}^{\prime} \mathrm{V}:\{[* \mathrm{~N} *]\}\left[\mathrm{vP} \mathrm{NP}_{1}\left[\mathrm{v}^{\prime}-\left[\mathrm{vP} \mathrm{NP}_{2}\left[\mathrm{v}^{\prime}-\mathrm{PP}\right]\right]\right]\right]\right]$ (gave Mary it to John)

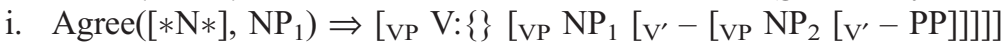

The resulting structure is shown in (20): it is a complete VP (it does not have any operation-inducing feature anymore) that can then be merged with some other head. The external argument NP is moved to the subject position (Spec,TP) in a subsequent movement step, yielding SVO order (rather than the VSO order that is the output of (19)). ${ }^{22}$

$$
\left[\mathrm{vP} \mathrm{V}\left[\mathrm{vP} \mathrm{NP}\left[\mathrm{v}^{\prime}-\left[\mathrm{vP} \mathrm{NP}\left[\mathrm{v}^{\prime}-\mathrm{PP}\right]\right]\right]\right]\right]
$$

\section{Noun-Phrase Structure by Reprojection}

So far we have seen that a reprojection approach to head movement in terms of Münchhausen features is both conceptually (see Surányi 2005) and empirically motivated (see Haider 2000, 2005, 2006). In this section, we show that assuming reprojection to also apply within NPs counters all arguments against NP as the highest projection of nominal projections that are based on movement of $\mathrm{N}^{23}$ We will in turn

${ }^{22}$ Note that the system does not necessarily have to predict VSO orders (although it seems to us that this consequence is innocuous, by and large). If external arguments are not subcategorized (see the previous footnote), this would be avoided. Alternatively, one might stipulate that all subcategorization features except for the most deeply embedded one are accompanied by a Münchhausen feature. This would exempt the external argument from special identification by $\mathrm{V}$, and thus capture the idea that this is what is special about external arguments (see, e.g., Williams's [1981] externalization convention).

${ }^{23} \mathrm{NP}$-shell analyses have been advanced to accommodate c-command relations between arguments of N in languages like English and German, where precedence implies c-command (as seen in the previous section for VPs in English); see Haider 2000 (based on nominal projections like (ia) in German) and Adger 2003 (based on nominal projections like (ib) in English), among others.

(i) a. die Wut des Mannes ${ }_{1}$ auf $\operatorname{sich}_{1}$ the anger of-the man on himself

b. the consul's gift of the gladiator ${ }_{1}$ to himself h $_{1}$

Of course, this can be implemented in the present approach in exactly the way that we have just seen with VPs. In contrast, in this section we focus on prenominal categories that are not $\theta$-marked by $\mathrm{N}$. 
analyze the Italian and Modern Hebrew data and the typological restrictions on word order in nominal projections presented in section 2 by using the system outlined in the previous section.

\subsection{Reprojection of $N$ in Italian}

Recall that Longobardi (1994) basically presupposes that there are two types of phonologically null $\mathrm{D}$ in Italian: Null $\mathrm{D}$ either receives a specific semantic interpretation as indefinite, or it has to be identified by $\mathrm{N}$ (the case of proper names). Longobardi suggests that an empty D can be identified by moving $\mathrm{N}$ to $\mathrm{D}$; such an analysis is not available for principled reasons if DP is a specifier of N. Thus, we would like to suggest that $\mathrm{D}$ identification by $\mathrm{N}$ is accomplished in another way - namely, by a designated categorial probe feature $[* \mathrm{D} *]$ that accompanies the subcategorization feature $[\bullet \mathrm{D} \bullet]$ on N. Just as in Longobardi's analysis, it must be assumed that this option is only available with proper names and if $\mathrm{D}$ needs to be identified by $\mathrm{N}$ in the first place (i.e., if $\mathrm{D}$ is not lexically filled). For the sake of concreteness, let us assume that $\mathrm{N}$ obligatorily has a subcategorization feature $[\bullet \mathrm{D} \bullet$ ] in Italian; and if $\mathrm{N}$ is a proper name, and the specific determiner that is selected is phonologically null, $\mathrm{N}$ must also be equipped with $[* \mathrm{D} *] .{ }^{24}$ It turns out that nothing more needs to be said to derive the pattern in (3).

As a case in point, consider the derivation of an NP like Gianni mio $(=(3 \mathrm{e}))$. By assumption, $\mathrm{N}$ always has a $[\bullet \mathrm{D} \bullet]$ feature. Given that $\mathrm{N}$ is a proper name and $\mathrm{D}$ is empty, $[* \mathrm{D} *]$ is also present on $\mathrm{N}$. Furthermore, $\mathrm{N}$ has a subcategorization feature $[\bullet A \bullet]$. $[\bullet A \bullet]$ is always higher on N's stack of structure-building features than $[\bullet \mathrm{D} \bullet$. The ensuing derivation is shown in (21).
a. N's feature set: $\{[\bullet \mathrm{A} \bullet] \succ[\bullet \mathrm{D} \bullet],[* \mathrm{D} *]\}$
b. $\operatorname{Merge}(\mathrm{N}:\{[\bullet A \bullet] \succ[\bullet \mathrm{D} \bullet],[* \mathrm{D} *]\}, \mathrm{AP}) \Rightarrow\left[\mathrm{N}^{\prime} \mathrm{AP} \mathrm{N}\right.$ : $\{[\bullet \mathrm{D} \bullet],[* \mathrm{D} *]\}]$
c. $\operatorname{Merge}\left(\left[\mathrm{N}^{\prime} \mathrm{AP} \mathrm{N}:\{[\bullet \mathrm{D} \bullet],[* \mathrm{D} *]\}\right], \mathrm{DP}\right) \Rightarrow\left[\mathrm{N}^{\prime} \mathrm{DP}\right.$ $\left[\mathrm{N}^{\prime}\right.$ AP N:\{[*D*]\}]]
d. $\operatorname{Move}\left(\mathrm{N}:\{[* \mathrm{D} *]\},\left[\mathrm{NP}\right.\right.$ DP $\left[\mathrm{N}^{\prime}\right.$ AP N $\left.\left.]\right]\right) \Rightarrow\left[\mathrm{N}^{\prime} \mathrm{N}\right.$ : $\left.\{[* \mathrm{D} *]\}\left[\mathrm{NP} \mathrm{DP}\left[\mathrm{N}^{\prime} \mathrm{AP}-\right]\right]\right]$
e. Agree $([* \mathrm{D} *], \mathrm{DP}) \Rightarrow\left[\mathrm{NP} \mathrm{N}:\{-\}\left[{ }_{\mathrm{NP}} \mathrm{DP}\left[\mathrm{N}^{\prime} \mathrm{AP}-\right]\right]\right]$
(Gianni D mio)

First, $\mathrm{N}$ is merged with AP (discharging $[\bullet \mathrm{A} \bullet]$ ), then with DP (discharging $[\bullet \mathrm{D} \bullet]$ ); empty D is a nonprojecting (trivial) phrase $(\mathrm{see}(21 \mathrm{~b}, \mathrm{c})$ ). This leaves the categorial probe feature $[* \mathrm{D} *]$ on $\mathrm{N}$ to be checked. Discharge is impossible with $\mathrm{N}$ in situ (due

\footnotetext{
${ }^{24}$ The question arises of how the dependence of $[* \mathrm{D} *]$ on phonologically null $\mathrm{D}$ can be expressed. One possible answer is that Münchhausen features are (generally) inserted in the numeration or lexical subarray (but before the derivation proper starts, in accordance with the Inclusiveness Condition; see Chomsky 2000, 2001 ); and in the case of proper names and D in Italian, $[* D *]$ is only inserted if $D$ is null (and therefore requires special identification). Alternatively, one might distinguish between two types of $[\bullet \mathrm{D} \bullet$ features; and $[* \mathrm{D} *]$ only shows up on proper name $\mathrm{N}$ if one of these two $[\bullet \mathrm{D} \bullet$ ]'s is present (namely, the one that selects an empty determiner).
} 
to a lack of c-command), so $\mathrm{N}$ moves and reprojects (see (21d)), which makes checking $[* \mathrm{D} *]$ possible (see (21e)). Thus, if there is an AP complement present in the structure, $\mathrm{N}$ remerges to c-command its specifier DP and to check $[* \mathrm{D} *]$; it then appears to the left of the adjective. If there is no $[\bullet A \bullet]$ to begin with (hence, no AP complement), $\mathrm{N}$ must still discharge its Münchhausen feature $[* \mathrm{D} *]$. However, this time, no movement is forced (and, therefore, it is blocked by Last Resort) because c-command obtains with $\mathrm{N}$ in situ.

\subsection{Reprojection of $N$ in Modern Hebrew}

Assuming the approach to CS nominals developed by Ritter (1988) to be essentially correct (see fn. 7), let us address the question of how it can be implemented in the present analysis. First, suppose that $\mathrm{N}$ has a categorial probe feature $[* \mathrm{D} *]$ in addition to its subcategorization feature $[\bullet D \bullet]$ in the presence of a genitive possessor-that is, in the context for construct state (see fn. 24 on how to express this correlation formally).

(22) Feature set of $\mathrm{N}$ in CS contexts

$$
\mathrm{N}:\{[\bullet \mathrm{N} \bullet] \succ[\bullet \mathrm{D} \bullet],[* \mathrm{D} *]\}
$$

The probe feature $[* \mathrm{D} *]$ triggers movement of $\mathrm{N}$ in CS environments because $[* \mathrm{D} *]$ cannot be checked in situ as $\mathrm{N}$ does not c-command its specifier DP. Therefore, reprojection movement of $\mathrm{N}$ is called for; and this produces the $\mathrm{N}$-initial word order. This is shown in (23) (the analysis here is simplified for the sake of exposition; e.g., the issue of genitive assignment to the possessor is ignored).

$$
\begin{aligned}
& {\left[\mathrm{NP}\left[\mathrm{N}_{1} \text { beyt }\right]\right.} \\
& \text { house } \\
& {[\mathrm{NP}[\mathrm{DP} \text { ha- }} \\
& \left.\left.\left.\left[\mathrm{N}^{\prime}\left[\mathrm{NP}_{2} \text { mora }\right]-\right]\right]\right]\right]
\end{aligned}
$$

'the house of the teacher'

Note that this analysis makes an interesting prediction: $\mathrm{D}$ and the genitive possessor automatically form a constitutent. Recall that to derive this, Ritter (1988) had to postulate a further postsyntactic operation ensuring that the definiteness marker $h a$ attaches to the possessor.

\subsection{Deriving the Constraints on Word-Order Variation}

Finally, we show how Cinque's (2005) and Abels \& Neeleman's (2006) analyses of the constraints on word-order variation within nominal projections can be implemented in the present approach. The following four assumptions are crucial in Abels \& Neeleman's reconstruction of Cinque's proposal, and it remains to be shown that the reprojection approach can derive the restrictions on this basis. 
(24) a. External Merge respects the hierarchical order $\mathrm{D} \succ \mathrm{n} \succ \mathrm{A} \succ \mathrm{N}$.

b. Movement ends in a c-commanding position.

c. Movement is leftward.

d. Movement in the nominal projection must involve a subtree containing $\mathrm{N}$.

(25) is a faithful adaptation of Abels \& Neeleman's (24a) to the present proposal, and $(24 \mathrm{~b}, \mathrm{c})$ can be adopted unchanged. ${ }^{25}$

(25) The hierarchy $[\bullet \mathrm{A} \bullet] \succ[\bullet \bullet] \succ[\bullet \mathrm{D} \bullet]$ must be respected on $\mathrm{N}$.

Of the four assumptions in (24), (25d) is the most stipulative: (24bc) are very general constraints on movement (and (24b) follows from the Strict Cycle Condition if Move is internal Merge); and (24a) (or (25)) is simply a fact about language that any theory must encode in some way. However, the constraint in (24d) is peculiar; in our view, it is the only conceptual blemish in Abels \& Neeleman's reconstruction of Cinque's approach. To the extent that it is true, it should be derived from more basic assumptions.

As it turns out, (24d) does not have to be stipulated in the present analysis; it follows as a theorem. Here is why: If $\mathrm{N}$ is the head of the nominal projection, all movements within this projection are either triggered by structure-building (movement-type-specific) specifier features on $\mathrm{N}$, or they are triggered by the need to get rid of categorial probe features (reprojection movement). The latter option can only be relevant for the head $\mathrm{N}$ itself (given the Strict Cycle Condition, nonheads cannot have operation-inducing features). ${ }^{26}$ The former option does not help in the case of A, n, and $\mathrm{D}$. Suppose for the sake of the argument that $\mathrm{N}$ bears some feature $[\bullet \mathrm{F} \bullet$ ] in addition to its subcategorization features for (say) A, n, and D that could in principle trigger movement $([\bullet \mathrm{F} \bullet]$ must then be embedded below subcategorization features in the stack of structure-building features); and that one of these categories (e.g., n) can actually provide a goal $[\mathrm{F}]$ for $[\bullet \mathrm{F} \bullet]$. $[\bullet \mathrm{F} \bullet]$ could still not trigger movement of $\mathrm{nP}$ across DP to an outer specifier of N (thereby giving rise to an unattested order) because the resulting configuration is structurally identical to the premovement configuration: If $\mathrm{nP}$ can check $\mathrm{N}$ 's $[\bullet \mathrm{F} \bullet$ ] feature in a derived specifier position, it can just as well check the same feature in situ (roughly, $[\bullet \mathrm{F} \bullet]$ on $\mathrm{X}$ is interpreted as

\footnotetext{
${ }^{25}$ Note that (25) is formulated in such a way as to ensure that not all of the subcategorization features do in fact have to show up on $\mathrm{N}$ all the time; cf. footnote 16 . Note also that arguments of $\mathrm{N}$ will be introduced by other subcategorization features that are higher on the hierarchy; so the hierarchy in (25) is only partial.

${ }^{26}$ Nothing in the present analysis excludes the possibility of structure-building features on D, n, and A, which may give rise to complex DPs (as in very few), $\mathrm{nP}$ (as in more than five), and APs (as in the German example seiner Frau treue 'his-DAT wife-DAT faithful-NOM'); or of probe (including, possibly, Münchhausen) features on these items, which may regulate internal agreement processes and which may in fact even trigger DP-, nP-, or AP-internal movement along the lines sketched here. However, none of these features can trigger structure-building in the nominal projection: Recall that we have assumed that the ultimate rationale of categorial probe (i.e., Münchhausen) features is to ensure a special identification of subcategorized elements. Therefore, the availability of a Münchhausen feature $[* \mathrm{~F} *]$ is intrinsically tied to the existence of a $[\bullet \mathrm{F} \bullet]$ feature on the same head - and, by assumption, the relevant structure-building features $([\bullet \mathrm{N} \bullet],[\bullet \mathrm{A} \bullet],[\bullet \bullet \bullet,[\bullet \mathrm{D} \bullet])$ are not present on $\mathrm{D}, \mathrm{n}$, or $\mathrm{A}$.
} 
"X wants to see $\mathrm{F}$ in its projection"- - but see the next subsection for a qualification). Consequently, movement is blocked by Last Resort in his case: When [ $\bullet \bullet \bullet$ becomes accessible on the stack of structure-building features, it can immediately be discharged, without any need for a syntactic movement operation, because the structural configuration required for discharge of $[\bullet \mathrm{F} \bullet]$ features is present in situ. ${ }^{27}$

Having laid out these premises, let us consider again the possible and impossible orders in nominal projections from the present perspective; (7) is repeated here as (26) (with roman numbers added in $\mathrm{Ib}$ for reasons that will become clear immediately).

(26) Possible and impossible orders in nominal projections

\begin{tabular}{|c||cccc|}
\hline Ia & D & n & A & N \\
& D & n & N & A \\
& D & A & N & n \\
& D & N & A & n \\
& N & A & n & D \\
& A & N & n & D \\
& n & A & N & D \\
& n & N & A & D \\
\hline
\end{tabular}

\begin{tabular}{|l||ccccc|}
\hline $\mathrm{II}$ & $*$ & $\mathrm{D}$ & $\mathrm{A}$ & $\mathrm{n}$ & $\mathrm{N}$ \\
& $*$ & $\mathrm{~A}$ & $\mathrm{D}$ & $\mathrm{n}$ & $\mathrm{N}$ \\
& $*$ & $\mathrm{n}$ & $\mathrm{A}$ & $\mathrm{D}$ & $\mathrm{N}$ \\
& $*$ & $\mathrm{~A}$ & $\mathrm{n}$ & $\mathrm{D}$ & $\mathrm{N}$ \\
& $*$ & $\mathrm{~A}$ & $\mathrm{D}$ & $\mathrm{N}$ & $\mathrm{n}$ \\
& $*$ & $\mathrm{n}$ & $\mathrm{D}$ & $\mathrm{A}$ & $\mathrm{N}$ \\
& $*$ & $\mathrm{n}$ & $\mathrm{D}$ & $\mathrm{N}$ & $\mathrm{A}$ \\
& $*$ & $\mathrm{~A}$ & $\mathrm{n}$ & $\mathrm{N}$ & $\mathrm{D}$ \\
& $*$ & $\mathrm{n}$ & $\mathrm{N}$ & $\mathrm{D}$ & $\mathrm{A}$ \\
& $*$ & $\mathrm{~N}$ & $\mathrm{n}$ & $\mathrm{D}$ & $\mathrm{A}$ \\
\hline
\end{tabular}

As in Abels \& Neeleman's (2006) analysis, the orders in Ia can be base-generated. Moreover, it can easily be verified (given the statements in $(24) /(25)$ ) that the orders in II cannot be generated. To give just one example: The order $\mathrm{D}-\mathrm{A}-\mathrm{n}-\mathrm{N}$ in II cannot be base-generated (A and $\mathrm{N}$ are not adjacent). Movement of $\mathrm{N}$ to the right periphery of the NP is impossible since all movement is leftward; and movement of A alone to the left is impossible because any feature that could trigger such a movement on $\mathrm{N}$ could be discharged with A remaining in situ. Similar conclusions apply in the case of all the other illegitimate orders in II.

The orders in Ib are the most interesting ones from the present perspective. They cannot be base-generated, and it therefore remains to be shown that they can be derived by (reprojection) movement. Three cases can be distinguished. First, consider the two orders (i) and (ii) in Ib. These orders can be derived if $\mathrm{N}$ has a Münchhausen feature $[* n *]$ requiring special identification of its second argument; given that $\mathrm{nP}$ is a specifier of $\mathrm{N}$ (and thus not c-commanded by $\mathrm{N}$ ), $\mathrm{N}$ undergoes reprojection movement in these cases to make Agree possible and discharge [*n*] (as soon as possible, given Agree over Merge). After reprojection, D is regularly merged. This is shown in (27) (the base order of AP and $\mathrm{N}$ is irrelevant).

\footnotetext{
${ }^{27}$ This reasoning is more or less the same as Abels (2003) gives in his account of Anti-Locality effects - extremely local movement is blocked because it does not create a new configuration for feature checking. Note incidentally that reprojection movement is compatible with this account of Anti-Locality (even though it is also highly local): The operation is triggered by Münchhausen features; it does create a new configuration for feature checking.
} 
(27) Orders (i), (ii)

(i) $\mathrm{D} \mathrm{N} \mathrm{n} \mathrm{A}$

$\mathrm{N}:\{[\bullet \mathrm{A} \bullet] \succ[\bullet n \bullet] \succ[\bullet \mathrm{D} \bullet],[* \mathrm{n} *]\}$

[NP DP [ $\left.\left.\mathrm{N}^{\prime} \mathrm{N}_{1}\left[\mathrm{NP} n P\left[\mathrm{~N}^{\prime}-\mathrm{AP}\right]\right]\right]\right]$

(ii) $\mathrm{N} n \mathrm{~A} \mathrm{D}$

$\mathrm{N}:\{[\bullet \mathrm{A} \bullet] \succ[\bullet \mathrm{n} \bullet] \succ[\bullet \mathrm{D} \bullet],[* \mathrm{n} *]\}$

$\left[\mathrm{NP}\left[\mathrm{N}^{\prime} \mathrm{N}_{1}\left[\mathrm{NP} \mathrm{nP}\left[\mathrm{N}^{\prime}-\mathrm{AP}\right]\right]\right] \mathrm{DP}\right]$

$\rightarrow \mathrm{N}$ moves in front of $\mathrm{n}$ initial specification derivation

$\rightarrow \mathrm{N}$ moves in front of $\mathrm{n}$ initial specification

derivation

The relevant step of the derivation of order (i) (and order (ii)) is illustrated in (28).

(28)

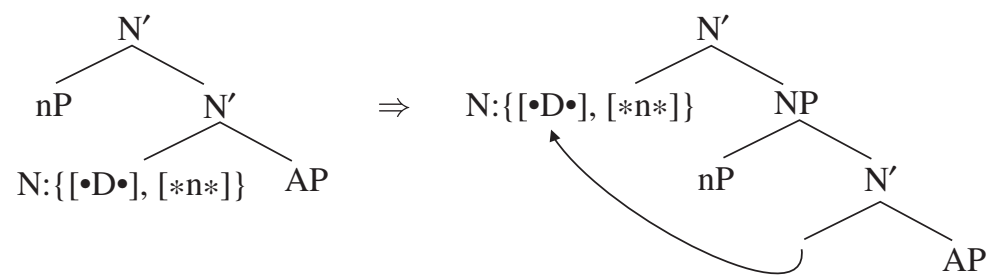

Let us turn next to a second pair, (iii) and (iv) in Ib. These orders come into existence when $\mathrm{N}$ is equipped with a categorial probe feature $[* \mathrm{D} *]$ (rather than $[* \mathrm{n} *]$, as in the previous case). Now $\mathrm{N}$ must remerge and reproject after being merged with DP; see (29).

(29) Orders (iii), (iv)

(iii) $\mathrm{N} \mathrm{D} \mathrm{n} \mathrm{A}$

$$
\begin{aligned}
& \mathrm{N}:\{[\bullet \mathrm{A} \bullet] \succ[\bullet \mathrm{n} \bullet] \succ[\bullet \mathrm{D} \bullet],[* \mathrm{D} *]\} \\
& \text { [NP } \left.\mathrm{N}_{1}\left[\mathrm{NP} \mathrm{DP}\left[\mathrm{N}^{\prime} \mathrm{nP}\left[\mathrm{N}^{\prime}-\mathrm{AP}\right]\right]\right]\right] \\
& \text { (iv) } \mathrm{N} \mathrm{D} \mathrm{A} \mathrm{n} \\
& \mathrm{N}:\{[\bullet \mathrm{A} \bullet] \succ[\bullet n \bullet] \succ[\bullet \mathrm{D} \bullet],[* \mathrm{D} *]\} \\
& \left.\left[\mathrm{NP}_{1} \mathrm{~N}_{\mathrm{NP}} \mathrm{DP}\left[\mathrm{N}^{\prime}\left[\mathrm{N}^{\prime}-\mathrm{A}\right] \mathrm{nP}\right]\right]\right]
\end{aligned}
$$

$\rightarrow \mathrm{N}$ moves in front of $\mathrm{D}$ initial specification derivation

$\rightarrow \mathrm{N}$ moves in front of $\mathrm{D}$ initial specification derivation

The crucial step of reprojection movement in the derivation of order (iii) is shown in (30).

(30)
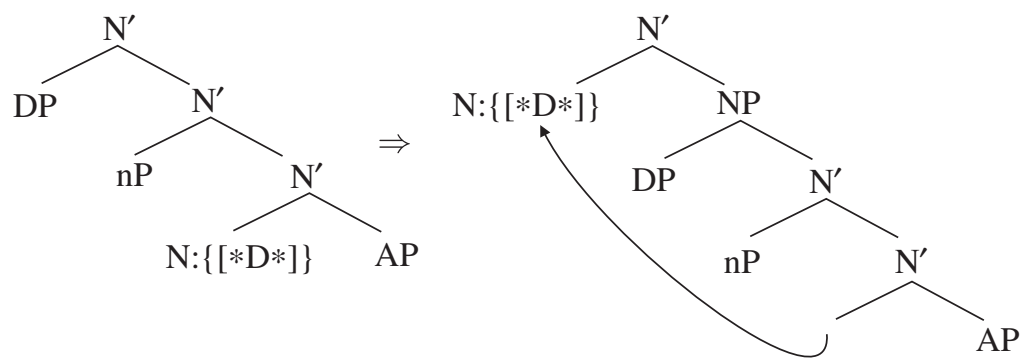
Finally, the orders in (v) and (vi) in $\mathrm{Ib}$ need to be derived. This time, the derivation is a bit more complex because no movement of a single $\mathrm{N}$ will be able to yield the surface strings where not only $\mathrm{N}$ but also A shows up outside of $\mathrm{D}$ and $\mathrm{n}$. These two cases require pied-piping: $\mathrm{N}$ pied-pipes $\mathrm{A}$ when it moves by reprojection. The question is how pied-piping can be effected in the present approach. We will adopt a standard analysis here according to which pied-piping involves feature percolation. ${ }^{28}$ Thus, suppose that a Münchhausen feature may in principle percolate to the immediately dominating category (in which case it is deleted on its original host). ${ }^{29}$ In the case at hand, this means that a feature like $[* \mathrm{D} *]$ may percolate from $\mathrm{N}$ to $\left[\mathrm{N}^{\prime} \mathrm{N}\right.$ AP] (or $\left[\mathrm{N}^{\prime} A P \mathrm{~N}\right]$ ). In languages that permit this operation, $\mathrm{N}^{\prime}$ effectively behaves as if it were a single head after percolation: It moves and reprojects to discharge $[* \mathrm{D} *]$ under c-command. As shown in (31), pied-piping of this type gives rise to the orders in (v) and (vi).

(31) Orders (v), (vi)

(v) N A D n $\rightarrow \mathrm{N}+\mathrm{A}$ moves in front of $\mathrm{D}$ $\mathrm{N}:\{[\bullet A \bullet] \succ[\bullet n \bullet] \succ[\bullet \mathrm{D} \bullet],[* \mathrm{D} *]\} \quad$ initial specification; $[* \mathrm{D} *]$ percolates $\left[\mathrm{NP}\left[\mathrm{N}^{\prime} \mathrm{N}\right.\right.$ AP] [NP DP [ $\left.\left.\left.\mathrm{N}^{\prime} \mathrm{nP}-\right]\right]\right]$

(vi) A N D n derivation $\mathrm{N}:\{[\bullet \mathrm{A} \bullet] \succ[\bullet n \bullet] \succ[\bullet \mathrm{D} \bullet],[* \mathrm{D} *]\} \quad$ initial specification; $[* \mathrm{D} *]$ percolates $\left[{ }_{\mathrm{NP}}\left[\mathrm{N}^{\prime}\right.\right.$ AP N] [NP DP [ $\left.\left.\left.\mathrm{N}^{\prime} \mathrm{nP}-\right]\right]\right]$ derivation

Note that percolation does not give rise to unwanted orders - still, only items that contain $\mathrm{N}$ can undergo movement, so all the orders in II remain excluded. To see this, suppose that an $[* \mathrm{n} *]$ feature (as it is required to generate the orders in (i) and (ii)) could also percolate. This would pose no particular problem (in the sense that unattested orders are generated), but it would not have any interesting consequence either-percolation of $[* \mathrm{n} *]$ cancels the effect that the Münchhausen feature is designed to have because reprojection movement would then be avoided. In this regard, a percolating $[* \mathrm{n} *]$ feature is just like a regular

\footnotetext{
28 Arguably, feature percolation is an additional mechanism that should be avoided if possible; see Heck 2004, 2007 and Cable 2007 for alternatives. However, for present purposes, assuming feature percolation may suffice.

${ }^{29}$ Recall that we have explicitly excluded this option in the case of structure-building features.
} 
$[* \mathrm{~A} *]$ feature (if the latter generates a complement, that is, if there is no $\theta$-marked argument of $\mathrm{N}$ present). ${ }^{30}$

\subsection{Edges of Nominal Projections}

The goal of this subsection is to address two issues that arise under the analysis presented so far, both of which turn out to be intimately related to the notion of "edge of a nominal projection." First, out of all logically possible permutations, the orders in Ia and $\mathrm{Ib}$ of (26) are the only unmarked, canonical orders for nominal projections (that can be used in information-structurally neutral contexts, etc.). However, as noted by Cinque (2005) and Abels \& Neeleman (2006), (some of) the orders in II of (26), while excluded as unmarked orders, are in fact attested as marked options in the world's languages; their occurrence usually goes hand in hand with information-structural effects. It remains to be seen how these marked orders can be derived in the present analysis. And second, as noted above (see fn. 4), it has sometimes been argued that parallels in extraction patterns between clauses and nominal projections support analogous functional structures: If clauses involve a CP layer on top of a verbal projection, so the argument goes, then there should also be a functional layer on top of a nominal projection. We address the two issues in turn.

\subsubsection{Movement to the edge}

Deviations from the unmarked $\operatorname{order}(\mathrm{s})$ of $\mathrm{D}, \mathrm{A}, \mathrm{n}$, and $\mathrm{N}$ within a nominal projection are sometimes possible in a language. Where they show up, the reordering is typically accompanied by information-structural (or related interpretive) effects, and it can be analyzed as involving the movement of some item to the edge of a nominal projection. Relevant examples come from Romanian (see Cinque 2004, 2005 and

\footnotetext{
${ }^{30}$ The analysis presented here differs from Abels \& Neeleman's approach to word-order restrictions in nominal projections in that it minimizes the occurrence of derivational ambiguities. A legitimate string involving $\mathrm{D}, \mathrm{n}, \mathrm{A}$, and $\mathrm{N}$ can often only have one possible source in the present framework. On the one hand, the strings in $\mathrm{Ib}$ are derived by reprojection movement and cannot be base-generated under present assumptions. On the other hand, most (but, as noted by a reviewer, not quite all) of the strings in Ia fail to be derivable by movement because, under present assumptions, the relevant movement operation would either qualify as too local (recall that a Münchhausen probe feature can only trigger movement of some item $\alpha$ in front of an XP that is not c-commanded by $\alpha$ in situ), or it would have to go to the right. This holds for the orders D-n-A-N, D-n-N-A, D-A-N-n, n-A-N-D, and n-N-A-D. (For instance, a derivation of D-n-NA from a base-generated $\mathrm{D}-\mathrm{n}-\mathrm{A}-\mathrm{N}$ would amount to a permutation of sisters, which cannot be effected by a Münchhausen feature, and the same goes for a derivation of $\mathrm{D}-\mathrm{A}-\mathrm{N}-\mathrm{n}$ from basic $\mathrm{D}-\mathrm{n}-\mathrm{A}-\mathrm{N}$ via pied-piping.) The only exceptions are the three orders $\mathrm{D}-\mathrm{N}-\mathrm{A}-\mathrm{n}$ (which can be base-generated or derived by $[* \mathrm{n} *]$-induced $\mathrm{N}$ movement to a position c-commanding $\mathrm{n}$ ); $\mathrm{A}-\mathrm{N}-\mathrm{n}-\mathrm{D}$ (which can be base-generated or derived by $[* \mathrm{D} *$-induced $\mathrm{A}-\mathrm{N}$ pied-piping movement to a position c-commanding $\mathrm{D}$; and, finally, $\mathrm{N}-\mathrm{A}-$ $\mathrm{n}-\mathrm{D}$ (which can be base-generated or derived - either by [*n*]-induced $\mathrm{N}$ movement to a position c-commanding $\mathrm{n}$, or by $[* \mathrm{D} *]$-induced $\mathrm{N}$ movement to a position c-commanding $\mathrm{D}$, or by $[* \mathrm{D} *]$-induced $\mathrm{N}-\mathrm{A}$ pied-piping movement to a position c-commanding D). More generally, in the present system a string containing $\mathrm{D}, \mathrm{n}, \mathrm{A}$, and $\mathrm{N}$ can be derived by base-generation and by movement only if (i) $\mathrm{N}$ precedes $\mathrm{n}$ and (ii) it is not the case that both $\mathrm{D}$ and $\mathrm{A}$ precede $\mathrm{N}$.
} 
references cited there); consider (32a), with an initial $\mathrm{N}$, and (32b), with an initial A (premovement positions are indicated by " ${ }_{\mathrm{n}}$ "; see fn. 18).
a. [distrugeri-le ${ }_{1}$ [acestea două cumplite $-_{1}$ ale oraşului destructions-the these two terrible of-the-city din cauza cutremurelor]] because-of-the-earthquakes 'these two terrible destructions of the city because of the earthquakes'

b. [frumoşi-i i $_{2}$ [doi -2 copii] $]$ beautiful-the two children 'these two beautiful children'

Assuming with Cinque that the base order in the Romanian nominal projection is $\mathrm{D}-\mathrm{n}-\mathrm{A}-\mathrm{N}$, (32ab) need to be derived by fronting of $\mathrm{N}$ and A, respectively. This is in principle unproblematic for $\mathrm{N}$ in (32a) ( $\mathrm{N}$ would just need to be optionally equipped with a Münchhausen $[* \mathrm{D} *]$ feature, yielding the regular order $\mathrm{N}-\mathrm{D}-\mathrm{n}-\mathrm{A}$ in Ib-(iii) of (26)), but something needs to be said about how the marked order A-D-n-N in (32b) can arise (which belongs to group II in (26)). A cannot bear a Münchhausen $[* \mathrm{D} *]$ feature (because $\mathrm{A}$ cannot have a structure-building feature $[\bullet \mathrm{D} \bullet]$ under the NP-over-DP hypothesis, and the former feature is parasitic on the latter), and, given the reasoning so far, any movement-inducing feature on $\mathrm{N}$ that might require $\mathrm{A}$ to show up in a specifier of $\mathrm{N}$ can be checked with $\mathrm{A}$ in situ.

A related problem arises with topicalization of possessors in Bulgarian nominal projections, as in (33ab) (see Dimitrova-Vulchanova \& Giusti 1999 and Alexiadou, Haegeman \& Stavrou 2007). Here, $\mathrm{PP}_{1}$ starts out as a sister of $\mathrm{N}$, so it is not quite clear how movement of $\mathrm{PP}_{1}$ to an outer specifier of $\mathrm{N}$ can give rise to a new checking configuration with $\mathrm{N}$ that does not obtain in the premovement structure.

$$
\begin{aligned}
& \text { a. tezi novi knigi }\left[\mathrm{PP}_{1}\right. \text { na Ivan] } \\
& \text { these new books to/of Ivan } \\
& \text { 'these new books of Ivan's' } \\
& \text { b. [[ } \left.\mathrm{PP}_{1} \text { na Ivan] [tezi novi knigi }-{ }_{1}\right] \\
& \text { to/of Ivan these new books } \\
& \text { 'these new books of Ivan's' }
\end{aligned}
$$

A German construction that is similar to the Bulgarian one in (33b) in that it involves nominal projection-internal topicalization of PPs is shown in (34a,b) (like its Bulgarian counterpart, such topicalization occurs predominantly with possessors, but, in contrast to what is the case in Bulgarian, it is not strictly confined to these items); see Tappe 1989, Lindauer 1995, and Bayer 1996 for extensive discussion of this (slightly substandard and distributionally somewhat restricted) construction. 


\author{
a. $\left[\left[\mathrm{PP}_{1}\right.\right.$ von Peter] [das Buch $\left.\left.-_{1}\right]\right]$ \\ of Peter the book \\ 'Peter's book' \\ b. [[ $\left[\mathrm{PP}_{1}\right.$ über Maria] [die Gerüchte $\left.-_{1}\right]$ ] \\ about Maria the rumors \\ 'the rumors about Maria'
}

Again, it is not immediately obvious how PP fronting can be effected in (34a,b) given that $\mathrm{PP}$ is in a local relation with $\mathrm{N}$ to begin with, and given that only $\mathrm{N}$ can trigger structure-building in the nominal projection. ${ }^{31}$

Any account of marked cases of fronting of AP, PP, and other categories in nominal projections in the present analysis should meet two requirements. First, it should maintain Cinque's and Abels \& Neeleman's results on possible and impossible canonical word orders in nominal projections (i.e., it should systematically distinguish the orders in Ia and Ib from those in II in (26)). Second, it should reflect the fact that it is a common property of these (and other) movements of non- $\mathrm{N}$ material in the nominal projection that they go hand in hand with informationstructural effects (an interpretation of the fronted item as topic, focus, or constrastive focus). Two kinds of approaches suggest themselves.

A first option (that has sometimes been pursued in the literature; see, e.g., Giusti 1996) would be to assume that in these cases, nominal projections have discourserelated functional heads on top of them that attract categories in an anti-local way. As far as we can see, such an approach would be formally compatible with what we have assumed so far; potential problems could only arise if the strict assumption is made that subcategorization of nominal projections by verbs is categorially uniform (because, e.g., V would need to be able to subcategorize for Top(N) or Foc $(\mathrm{N})$ instead of just N). Still, one might argue that this solution would amount to letting in the DP hypothesis through the back door, with functional structure on top of NP emerging as a possibility for nominal projections after all.

A second option, which we adopt here (building essentially on Chomsky 2001), is to assume that there are certain structure-building features triggering movement that can only be discharged at the edge of a phase, conceived of as the outermost specifier of a phase, and not just with any local specifier or complement; these edge features

\footnotetext{
${ }^{31}$ As it stands, the only kind of (non-N) movement in a nominal projection that is entirely unproblematic is movement from within a complement (or, depending on the exact formulation of the Condition on Extraction Domain [CED], specifier) of N, as in (i) in German.

(i) $\left[\mathrm{da}_{1} \quad\right.$ [ein Buch $[\mathrm{PP}-1$ über $\left.\left.]\right]\right]$ there/it a book about

Given a nonrecursive concept of saturation of structure-building features, an item such as $d a$ in (i) cannot satisfy N's demands if it shows up in a PP that acts as a complement of N.
} 
(which we note as $[\bullet \mathrm{E} \bullet]$ ) necessarily trigger certain interpretational effects related to notions like topic and focus. ${ }^{32}$

On this view, there is a parallelism between movement to the edge of NP and movement to the edge of the (highest) VP projection (i.e., of what replaces vP in the reprojection approach to the structure of verbal projections sketched in subsection 3.4): The typical movement operations that target VP (vP) edges are scrambling and object shift, both of which are known to be correlated with information-structural effects in roughly the same way that types of NP-internal fronting as discussed in this section are.

More generally, we can maintain that the pattern in (26) is real and that it is derived under the version of the NP-over-DP analysis adopted here; the only qualification is that information structure-related movement (triggered by designated edge features) may lead to orders of the type in II, which are thus available as noncanonical, marked orders.

\subsubsection{Movement from the edge}

Given that edge $([\bullet \mathrm{E} \bullet])$ features can only show up on phase heads, the preceding discussion presupposes that NP acts as a phase; see Svenonius 2004, Heck \& Zimmermann 2004, and Matushansky 2005, among others, for arguments that the head of a nominal projection does indeed have typical phase properties. ${ }^{33}$ We would like to contend that it is the phase status of NP that is ultimately responsible for parallels between extraction from nominal projections and extraction from clauses, and that these parallels therefore do not support the existence of functional material on top of NPs in nominal projections; in particular, these parallels do not provide arguments for the DP hypothesis (as assumed by Szabolcsi [1994] and Alexiadou, Haegeman \& Stavrou [2007], among many others).

An argument for the parallel behavior of nominal projections and clauses with respect to extraction based on Greek data can be found in Horrocks \& Stavrou 1987 and Alexiadou, Haegeman \& Stavrou 2007. Greek has a nominal projection-internal focus-related fronting operation that is similar to the German and Bulgarian constructions just discussed. Furthermore, in Greek nominal projections, a

\footnotetext{
${ }^{32}$ Also see den Dikken 2007:153 for essentially this reasoning. The notion of edge employed here is somewhat stricter than the one in Chomsky 2001; it resembles Chomsky's notion of (phonological) border. Still, this does not mean that multiple edge feature-driven movement in a phase is impossible. Given incremental structure-building, an edge feature can be satisfied by movement of some item $\alpha$, and a further edge feature may then trigger movement of some other item $\beta$ to a higher specifier: Each operation is locally well-formed (i.e., ending up in the edge domain) in the derivation, even though the strict edge property of some item may eventually be obliterated by further movement. Such $[\bullet \mathrm{E} \bullet$ features are either inherently lowest ranked on stacks of structure-building features, or they may be inserted in the course of the derivation (as envisaged by Chomsky [2001, 2005a]). Thus, if, say, N in Romanian has merged with AP, $\mathrm{nP}$, and DP and is equipped with an $[\bullet \mathrm{E} \bullet]$ feature at this point, an AP may undergo fronting to the (current) edge position of the NP, thereby creating an outermost specifier and triggering information structure-related interpretational effects. Similar derivations are available for NP-internal PP fronting in Bulgarian and German.

${ }^{33}$ These arguments rely on the DP hypothesis, but most of them can be maintained under an NP-over-DP approach.
} 
wh-possessor may occur either at the left edge of the projection, in front of a determiner, or in situ, to the right of N. Horrocks \& Stavrou point out that this alternation finds a parallel in the distribution of $w h$-phrases in clauses, which may either show up in the Spec,CP position or in situ (yielding an echo interpretation in the latter case). Furthermore, they point out that not only can both a nominal projection in which a $w h$-possessor shows up in situ and a nominal projection in which a $w h$-possessor shows up at the left edge undergo wh-movement in clauses; what is more, the wh-possessor itself can also be extracted (in violation of the Left Branch Condition) to the Spec,CP position of a clause; see (35). This might plausibly be interpreted in such a way that nominal projection-internal fronting of $w h$-possessors feeds subsequent $w h$-movement; Horrocks \& Stavrou (1987) and Alexiadou, Haegeman \& Stavrou (2007) conclude that it provides an argument for a specifier position of DP that acts as an escape hatch. ${ }^{34}$

$$
\begin{aligned}
& \text { a. [To vivlio tinos } \left.\mathrm{T}_{2}\right] \mathrm{mu} \text { ipes }\left[\mathrm{CP}^{-}{ }_{1}^{\prime} \text { pos dhjavases }-_{1}\right] \text { ? } \\
& \text { the book who-GEN me-GEN said-2.SG that read-2.SG } \\
& \text { b. }\left[\operatorname{Tinos}_{2} \text { to vivlio }-_{2}\right] \mathrm{mu} \text { ipes }\left[\mathrm{CP}^{-}{ }_{1}^{\prime} \text { pos dhjavases }-_{1}\right] \text { ? } \\
& \text { who-GEN the book me-GEN said-2.SG that read-2.SG } \\
& \text { c. } \operatorname{Tinos}_{2} \mathrm{mu} \text { ipes }\left[\mathrm{CP}-_{2}^{\prime \prime} \text { pos dhjavases }\left[-_{2}^{\prime} \text { to vivlio }-_{2}\right]\right] \text { ? } \\
& \text { who-GEN me-GEN said-2.SG that read-2.SG the book }
\end{aligned}
$$

The first thing to note is that this argument in support of the DP hypothesis relies on the assumption that there are no multiple specifiers; if there are, it cannot be maintained. Furthermore, even assuming that the $w h$-possessor in (35c) must move to Spec,CP via a left-peripheral position in the nominal projection (which follows from a parametrized version of the Subjacency Condition in Horrocks \& Stavrou's original paper), the conclusion that the $w h$-possessor in (35c) can only use the intermediate nominal projection-internal escape hatch because it may also show up overtly in this position may be suggestive, but it does not follow in the strict sense (after all, wh-phrases can undergo successive-cyclic movement via Spec,CP positions of declarative clauses in which they can never show up overtly, in languages like English). These reservations notwithstanding, it can be noted that the necessity of successive-cyclic extraction via the left edge of the nominal projection (NP, in the present approach) follows immediately from the Phase Impenetrability Condition (PIC; Chomsky 2001, 2005a), according to which the c-command domain of a head $\mathrm{X}$ of a phase XP is not accessible to operations outside XP (only X and its edge are accessible to such operations). If NP is a phase, extraction from NP can only take place via the edge of NP.

A similar conclusion can be drawn for the well-known possessor extraction facts of Hungarian (see Szabolcsi 1994). A prenominal possessor may show up with nominative Case, in a position following the determiner, or with dative Case, in an edge positition preceding it. Interestingly, only in the latter case can the possessor be moved into the clausal domain; cf. $(36 a, b)$.

${ }^{34}$ The Bulgarian construction addressed in the previous subsection instantiates a similar pattern. 


\begin{tabular}{|c|c|c|c|}
\hline Mari-nak 1 & Peter & látta $\left[-{ }_{1} \mathrm{a}\right.$ & kalapja] \\
\hline Mari-DAT & Peter-NOM & saw & hat \\
\hline 'Peter saw & Mari's hat.' & & \\
\hline$*$ Mari $_{1}$ & Peter & látta $[\mathrm{a}-1$ & kalapja] \\
\hline Mari-NOM & Peter-NOM & saw the & hat \\
\hline
\end{tabular}

Again, given that NPs are phases, and given that multiple specifiers are systematically available, there is no need to assume a functional layer with a Comp-like escape hatch on the basis of these data. The PIC will ensure that only items that occupy the edge domain of the nominal projection can leave it. Both the standard account in terms of a functional DP layer and the present account in terms of multiple $\mathrm{N}$ specifiers must somehow exclude the possibility that an edge feature can be established in the nominal projection for the nominative possessor in (36b); in both cases, the analysis might ultimately correlate the effect in (36b) with complementizer-trace effects as they can be observed in English. ${ }^{35}$

To sum up so far, to the extent that clauses and nominal projections behave similarly with respect to extraction, this is due to the fact that they both qualify as phases. The same conclusion can be drawn for instances of parallel behavior of nominal projections and verbal projections with respect to information structurerelated projection-internal fronting as discussed in the previous subsection.

Apart from that, it is worth pointing out that there are also a number of asymmetries between extraction from nominal projections and extraction from clauses. As a general tendency, extraction from clauses obeys the following generalization: The lower an argument is in the structure, the more likely it is that it can be extracted; compare, for example, complementizer-trace effects, which distinguish mobile objects from immobile subjects. In contrast, a reverse general tendency can be observed for nominal projections: The higher an argument is in the structure, the more likely it is that it can be extracted. Thus, as has been observed by Cinque (1980) for Italian and by Shlonsky (1988) for Hebrew, the presence of a possessor in a nominal projection blocks extraction of lower subject (agent) and

\footnotetext{
35 Alexiadou, Haegeman \& Stavrou (2007) provide an independent argument for the existence of a functional layer on top of NP that is based on extraction facts: Unlike articles (which are D items), demonstratives (which are assumed to be specifiers of an empty D) can block extraction from a nominal projection. This is analyzed in the same way that wh-island effects are traditionally analyzed, with a $w h$-item blocking an escape hatch. Again, this argument breaks down when multiple specifiers are adopted. Current analyses of the $w h$-island effect treat it as a minimality/intervention phenomenon, and not in terms of an escape hatch that is blocked; and whereas the escape hatch approach envisages an explicit competition of two items for a single position (thereby potentially supporting a DP layer), the minimality approach does not-it just relies on asymmetric c-command of items competing for movement. Furthermore, an alternative account of the blocking effect of demonstratives is readily available. If, for example, etu knigu (thisACC book-ACC) in Russian blocks extraction from NP whereas knigu (with an empty determiner) does not (see Alexiadou, Haegeman \& Stavrou 2007:220), this may be related to different degrees of specificity; and specific nominal projections are generally known to block extraction (see, e.g., Mahajan 1992 and Diesing 1992 for approaches to locality from which this follows - essentially, the idea is that a specific nominal projection occupies a specifier position that a nonspecific nominal projection does not have to show up in, which derives the barrier status of the former, given the CED).
} 
object (theme) arguments; and the presence of a subject argument blocks extraction of a lower object argument. ${ }^{36}$ We cannot offer a full-fledged analysis of these asymmetries here, but one might speculate that the difference can ultimately be traced back to the question of whether the phase head is a lexical $(\mathrm{N}, \mathrm{V}(\mathrm{v}))$ or functional $(\mathrm{C})$ category: Whereas the phase heads $\mathrm{N}$ and $\mathrm{V}$ themselves introduce (via subcategorization features) the arguments that need to be moved to the phase edge, $\mathrm{C}$ does not; and whereas edge feature insertion (of the type that triggers intermediate movement steps) seems to obey strict locality with subcategorized items (in some languages), it appears to be governed by an anti-locality requirement with items that are not subcategorized by the phase head (again, only in some languages, given that not all languages that have subject raising to Spec,TP exhibit complementizer-trace effects).

Finally, we would like to emphasize that many other differences between nominal projections and clauses need to be accounted for, which would seem to support a different treatment of the two categories (see, e.g., the absence of raising in nominal projections, which might be taken to suggest the absence of functional structure on top of NPs, compared with systematic movement to Spec,TP in clauses; see Williams 1982). However, a proper analysis of these asymmetries between nominal projections and clauses would lead us too far astray here.

\section{Conclusion}

To sum up, we have sketched an approach to reprojection that relies on what we call Münchhausen features - that is, categorial probe features that target arguments that have just been merged (as a consequence of discharge of a structure-building feature). We have argued that there is good reason to assume reprojection movement of $\mathrm{N}$ in the nominal domain: If we do so, one of the strongest types of argument in support of a DP-over-NP approach (the DP hypothesis) loses its force (namely, that there is good evidence for movement of $\mathrm{N}$, and that $\mathrm{D}$ is needed to provide a landing site), and an NP-over-DP approach can in principle be entertained. We have also shown that assuming an NP-over-DP approach with reprojection movement of $\mathrm{N}$ driven by categorial probe features makes it possible to independently derive the one of the four assumptions in Abels \& Neeleman's reconstruction of Cinque's approach to wordorder variation in nominal projections (see (24)) that looks stipulative (namely, that movement in the nominal projection must involve a subtree containing $\mathrm{N}$; (24d)). In our view, this is the most important result of the present paper, and to the extent that (24d) must resist a principled explanation in DP-over-NP approaches, it presents a strong argument for NP-over-DP approaches.

Needless to say, if NP-over-DP approaches are to qualify as viable alternatives to standard DP-over-NP approaches, many more arguments for the DP hypothesis that have been brought forward in the literature must be addressed. Many of the original arguments given in support of the DP hypthesis center around data where more than

${ }^{36}$ Of course, just as there are languages that permit movement of both objects and subjects in clauses (and languages that permit movement of neither), there are languages in which the extractability hierarchy does not hold for NPs - German, for example, is a language in which neither effect can be observed. 
one item precedes N (cf. Abney 1987, Haider 1988, and Szabolcsi 1994, among many others). As noted, these arguments lose their force if a multiple specifier approach is adopted - under this assumption, NPs with more than one prenominal category can receive essentially the same structural analysis that they did in Jackendoff 1977. Certain other arguments may not have been particularly convincing from the very beginning; among them is Abney's argument based on gerunds (where $\mathrm{V}$ movement to $\mathrm{D}$ can easily be reinterpreted as V movement to N; see Stechow 1992). Furthermore, agreement phenomena in nominal projections (in languages like Hungarian, Turkish, Yupik, and Tzutujil) have been assumed to provide arguments for the DP hypothesis (cf. Abney 1987 and subsequent work based on it), but again, it seems to us that they do not presuppose the existence of a functional head that mediates this agreement, and that closer scrutiny in fact reveals that they pose more problems than they solve (particularly if one adopts an Agree-based approach, where the concept of "mediation" is difficult to make sense of). Of course, there are many other arguments for the DP hypothesis that need to be tackled to prove the competing (and traditional) approach viable (see, e.g., Alexiadou, Haegeman \& Stavrou 2007).

Then again, there have always been arguments against the DP hypothesis that, in our view, have not yet been convincingly rejected. For instance, facts about selection would seem to initially support the view that $\mathrm{V}$ embeds $\mathrm{N}$ rather than $\mathrm{D}$ in the unmarked case (see Grimshaw 2000). Similarly, facts about incorporation would seem to support an NP-over-DP approach (see Baker 1988, 1996; Baker \& Hale 1990; Rosen 1990; and Payne 1993): Incorporation of N into V may strand D in the nominal projection. Assuming that incorporation is head movement, this is unexpected under the DP hypothesis (since a Head Movement Constraint violation should occur) but unproblematic if the DP hypothesis is abandoned. ${ }^{37}$ However, addressing further evidence for or against the DP hypothesis is clearly beyond the scope of the present paper. ${ }^{38}$ The same goes for extensions in various directions that the present proposal would have to undergo to qualify as a comprehensive approach to nominal projections. ${ }^{39}$ Here we have confined ourselves to showing that generating $\mathrm{NP}$ structure by reprojection of $\mathrm{N}$ offers a viable alternative to $\mathrm{N}$ movement to $\mathrm{D}$ (and other functional projections) - an alternative that makes it possible to derive an

\footnotetext{
${ }^{37}$ We hasten to add that such a reasoning is, of course, only compatible with the present approach if one assumes that head movement for the purposes of noun incorporation is possible after all, and if one finds a way to evade the problems related to strict cyclicity and c-command mentioned above (in contrast to the kind of head movement that does not involve incorporation into a lexical category, which we have been exclusively concerned with in this article). It has sometimes been suggested that there are indeed two separate kinds of head movement that encode the relevant differences (see, e.g., Roberts 2001), so we take the enterprise to be far from hopeless.

${ }^{38}$ See, for example, Payne 1993 for further empirical arguments against a DP-over-NP analysis, and Alexiadou, Haegeman \& Stavrou 2007:89ff. for extensive discussion.

${ }^{39}$ For instance, we have not been concerned with questions of morphological realization of morphosyntactic features in nominal projections, including the phenomenon of expletive or doubled articles in a variety of languages, among them Greek (see Alexiadou \& Wilder 1998) and Swedish (see, e.g., Hankamer \& Mikkelsen 2005 and Heck et al. 2008); also see Alexiadou 2007 for general remarks. We believe that the present analysis is in principle compatible with most existing morphological theories, including a late insertion approach along the lines of Distributed Morphology, provided that either feature bundles of syntactic categories can be targets for lexical insertion (see Noyer 1992) or that functional morphemes can be added postsyntactically (e.g., by dissociation, as in Embick \& Noyer 2001).
} 
otherwise stipulative statement needed in Abels \& Neeleman's and Cinque's approaches to word-order variation in nominal projections.

\section{References}

Abels, K. 2003. Successive cyclicity, anti-locality, and adposition stranding. Ph.D. dissertation, University of Connecticut, Storrs.

Abels, K. \& A. Neeleman. 2006 Universal 20 without the LCA. Ms., University of Tromsø and University College London.

Abney, S. 1987. The English noun phrase in its sentential aspect. Ph.D. dissertation, MIT, Cambridge, MA.

Ackema, P., A. Neeleman \& F. Weerman. 1993. Deriving functional projections. In Proceedings of NELS 23:17-31. Amherst, MA: GLSA Publications.

Adger, D. 2003. Core syntax. Oxford: Oxford University Press.

Alexiadou, A. 2001. Adjective syntax and noun raising. Studia Linguistica 55:217-248.

Alexiadou, A. 2007. On the cross-linguistic distribution of (in)definiteness spreading. Ms., Universität Stuttgart.

Alexiadou, A. \& C. Wilder. 1998. Adjectival modification and multiple determiners. In Possessors, predicates, and movement in the DP, ed. A. Alexiadou \& C. Wilder, 303-332. Amsterdam: John Benjamins.

Alexiadou, A., L. Haegeman \& M. Stavrou. 2007. Noun phrase in the generative perspective. Berlin: Mouton de Gruyter.

Baker, M. 1988. Incorporation: A theory of grammatical function changing. Chicago: University of Chicago Press.

Baker, M. 1996. The polysynthesis parameter. Oxford: Oxford University Press.

Baker, M. \& K. Hale. 1990. Relativized Minimality and pronoun incorporation. Linguistic Inquiry 21:289-297.

Bayer, J. 1996. Directionality and Logical Form: On the scope of focusing particles and wh-insitu. Dordrecht: Kluwer.

Bayer, J. \& E. Brandner. 2008. On wh-head-movement and the Doubly-Filled-Comp Filter. In Proceedings of the 26th West Coast Conference on Formal Linguistics, ed. C. B. Chang \& H. J. Haynie, 87-95. Somerville, MA: Cascadilla Proceedings Project.

Bhatt, R. 2002. The raising analysis of relative clauses. Natural Language Semantics 10:43-90.

Bobaljik, J. 1999. Adverbs: The hierarchy paradox. Glot International 4.9/10:27-28.

Borer, H. 1999. Deconstructing the construct. In Beyond principles and parameters, ed. K. Johnson \& I. Roberts, 43-90. Dordrecht: Kluwer.

Brody, M. 2003. Towards an elegant syntax. London: Routledge.

Bury, D. 2003. Phrase structure and derived heads. Ph.D. dissertation, University College London.

Cable, S. 2007. The grammar of Q. Ph.D. dissertation, MIT, Cambridge, MA.

Chomsky, N. 1973. Conditions on transformations. In A festschrift for Morris Halle, ed. S. Anderson \& P. Kiparsky, 232-286. San Diego, CA: Academic Press.

Chomsky, N. 1986. Barriers. Cambridge, MA: MIT Press.

Chomsky, N. 1995. The Minimalist Program. Cambridge, MA: MIT Press.

Chomsky, N. 2000. Minimalist inquiries: The framework. In Step by step, ed. R. Martin, D. Michaels \& J. Uriagereka, 89-155. Cambridge, MA: MIT Press.

Chomsky, N. 2001. Derivation by phase. In Ken Hale: A life in language, ed. M. Kenstowicz, 1-52. Cambridge, MA: MIT Press.

Chomsky, N. 2005a. On phases. Ms., MIT, Cambridge, MA.

Chomsky, N. 2005b. Three factors in language design. Linguistic Inquiry 36:1-22.

Chomsky, N. 2007. Approaching UG from below. In Interfaces + recursion = language?, ed. U. Sauerland \& H.-M. Gärtner, 1-31. Berlin: Mouton de Gruyter.

Cinque, G. 1980. On extraction from NP in Italian. Journal of Italian Linguistics 1/2:47-99. 
Cinque, G. 2004. A phrasal movement analysis of the Romanian DP. In Studia linguistica et philologica in honorem D. Irimia, ed. A.-M. Minut \& E. Monteanu, 129-142. Iaşi, Romania: Editura Universitătii "A.I.Cuza."

Cinque, G. 2005. Deriving Greenberg's Universal 20 and its exceptions. Linguistic Inquiry 36:315-323.

Collins, C. 2003. Eliminating labels. In Derivation and explanation in the Minimalist Program, ed. S. D. Epstein \& T. D. Seely, 42-64. Oxford: Blackwell.

Diesing, M. 1992. Indefinites. Cambridge, MA: MIT Press.

den Dikken, M. 2007. Phase extension: A reply. Theoretical Linguistics 33:133-163.

Dimitrova-Vulchanova, M. \& G. Giusti. 1999. Possessors in the Bulgarian DP. In Topics in South Slavic syntax and semantics, ed. M. Dimitrova-Vulchanova \& L. Hellan, 163-192. Amsterdam: John Benjamins.

Donati, C. 2006. On wh-head movement. In Wh-movement: Moving on, ed. L. Cheng \& N. Corver, 21-46. Cambridge, MA: MIT Press.

Embick, D. \& R. Noyer. 2001. Movement operations after syntax. Linguistic Inquiry 32:555595.

Epstein, S., E. Groat, R. Kawashima \& H. Kitahara. 1998. A derivational approach to syntactic relations. Oxford: Oxford University Press.

Fanselow, G. 2003. Münchhausen-style head movement and the analysis of Verb-Second. In Head movement and syntactic theory, ed. A. Mahajan, Syntax at sunset 3, 40-76. Los Angeles \& Potsdam: UCLA \& Universität Potsdam Working Papers in Linguistics.

Franks, S. \& A. Pereltsvaig. 2004. Functional categories in the nominal domain. In Proceedings of FASL 12, ed. O. Arnaudova, W. Browne, M. L. Rivero \& D. Stojanovic, 109-128. Ottawa: University of Ottawa.

Gärtner, H.-M. 2002. Generalized transformations and beyond. Berlin: Akademie-Verlag.

Giusti, G. 1996. Is there a FocusP and a TopicP in the noun phrase structure? University of Venice Working Papers in Linguistics 6(2):105-128.

Grimshaw, J. 2000. Extended projection and locality. In Lexical specification and insertion, ed. P. Coopmans, M. Everaert \& J. Grimshaw, 115-133. Amsterdam: John Benjamins.

Haider, H. 1988. Zur Struktur der deutschen Nominalphrase. Zeitschrift für Sprachwissenschaft $7: 32-59$.

Haider, H. 2000. Branching and discharge. In Lexical specification and insertion, ed. P. Coopmans, M. Everaert \& J. Grimshaw, 135-164. Amsterdam: John Benjamins.

Haider, H. 2005. How to turn German into Icelandic-and derive the OV/VO contrasts. Journal of Comparative Germanic Linguistics 8:1-53.

Haider, H. 2006. Zufall und Notwendigkeit bei der germanischen VO/OV-Spaltung. Ms., Universität Salzburg.

Hankamer, J. \& L. Mikkelsen. 2005. When movement must be blocked: A reply to Embick and Noyer. Linguistic Inquiry 36:85-125.

Harley, H. 1995. Subjects, events, and licensing. Ph.D. dissertation, MIT, Cambridge, MA.

Heck, F. 2004. A theory of pied piping. Ph.D. dissertation, Universität Tübingen.

Heck, F. 2007. On certain properties of pied piping. Ms., Universität Leipzig. To appear in Linguistic Inquiry.

Heck, F. \& G. Müller. 2003. Derivational optimization of wh-movement. Linguistic Analysis 33:97-148.

Heck, F. \& G. Müller. 2007. Extremely local optimization. Proceedings of WECOL 2006. Fresno, CA: California State University.

Heck, F. \& M. Zimmermann. 2004. DPs as phases. Ms., Universität Leipzig and HU Berlin.

Heck, F., G. Müller \& J. Trommer. 2008. A phase-based approach to Scandinavian definiteness marking. In Proceedings of the 26th West Coast Conference on Formal Linguistics, ed. C. B. Chang \& H. J. Haynie, 226-233. Somerville, MA: Cascadilla Proceedings Project.

Holmberg, A. 1991. Head scrambling. Handout of talk at GLOW 1991 (Leiden). 
Hornstein, N. \& J. Uriagereka. 2002. Reprojections. In Derivation and explanation in the Minimalist Program, ed. S. D. Epstein \& T. D. Seely, 106-132. Oxford: Blackwell.

Horrocks, G. \& M. Stavrou. 1987. Bounding theory and Greek syntax: Evidence for wh-movement in NP. Journal of Linguistics 23:79-108.

Jackendoff, R. 1977. X-bar syntax: A study of phrase structure. Cambridge, MA: MIT Press.

Kayne, R. 1994. The antisymmetry of syntax. Cambridge, MA: MIT Press.

Kobele, G. 2006. Generating copies. Ph.D. dissertation, UCLA.

Koeneman, O. 2000. The flexible nature of verb movement. Ph.D. dissertation, Utrecht University.

Koopman, H. \& A. Szabolcsi. 2000. Verbal complexes. Cambridge, MA: MIT Press.

Kratzer, A. 1996. Severing the external argument from its verb. In Phrase structure and the lexicon, ed. J. Rooryck \& L. Zaring, 109-137. Dordrecht: Kluwer.

Laenzlinger, C. 2005. French adjective ordering: Perspectives on DP-internal movement types. Lingua 115:649-689.

Lahne, A. 2006. A CP approach to left peripheral architecture. Ms., Universität Leipzig.

Larson, R. 1988. On the double object construction. Linguistic Inquiry 19:335-391.

Larson, R. 2004. The projection of DP. Ms., Stony Brook University, New York.

Lechner, W. 2004. Extending and reducing the MLC. In Minimality effects in syntax, ed. A. Stepanov, G. Fanselow \& R. Vogel, 205-240. Berlin: Mouton de Gruyter.

Lewis, D. 1972. General semantics. In Semantics of natural language, ed. D. Davidson \& G. Harman. 169-218. Dordrecht: Reidel.

Lindauer, T. 1995. Genitivattribute: Eine morphosyntaktische Untersuchung zum deutschen $D P / N P$-System. Tübingen: Niemeyer.

Longobardi, G. 1994. Reference and proper names: A theory of N-movement in syntax and Logical Form. Linguistic Inquiry 25:609-665.

Mahajan, A. 1992. The Specificity Condition and the CED. Linguistic Inquiry 23:510-516.

Mahajan, A. 2003. Word order and (remnant) VP movement. In Word order and scrambling, ed. S. Karimi, 217-237. Oxford: Blackwell.

Matushansky, O. 2005. Going through a phase. MIT Working Papers in Linguistics 49:157181. Cambridge, MA: MITWPL.

Matushansky, O. 2006. Head-movement in linguistic theory. Linguistic Inquiry 37:69-109.

Müller, G. 1998. Incomplete category fronting. Dordrecht: Kluwer.

Müller, G. 2004. Verb-Second as vP-First. Journal of Comparative Germanic Linguistics 7:179-234.

Müller, G. 2007. On deriving CED effects from the PIC. Talk at GLOW, Tromsø. Ms., Universität Leipzig.

Noyer, R. 1992. Features, positions, and affixes in autonomous morphological structure. Ph.D. dissertation, MIT, Cambridge, MA.

Nunes, J. 2004. Linearization of chains and sideward movement. Cambridge, MA: MIT Press.

Payne, J. 1993. The headedness of noun phrases: Slaying the nominal Hydra. In Heads in grammatical theory, ed. G. Corbett, N. Fraser \& S. McGlashan, 114-139. Cambridge: Cambridge University Press.

Pereltsvaig, A. 2006a. Head movement in Hebrew nominals: A reply to Shlonsky. Lingua 116:A1-A40.

Pereltsvaig, A. 2006b. Small nominals. Natural Language \& Linguistic Theory 24:433-500.

Pesetsky, D. 1985. Morphology and Logical Form. Linguistic Inquiry 16:193-246.

Pesetsky, D. \& E. Torrego. 2006. Probes, goals, and syntactic categories. Ms., MIT, Cambridge, MA. Lingbuzz/000321.

Pollard, C. J. \& I. A. Sag. 1994. Head-Driven Phrase Structure Grammar. Chicago: University of Chicago Press.

Prince, A. \& P. Smolensky. 2004. Optimality Theory: Constraint interaction in generative grammar. Oxford: Blackwell.

Ramchand, G. 2003. First phase syntax. Ms., Oxford University. 
Richards, M. 2007. On feature inheritance. Linguistic Inquiry 38:563-572.

Ritter, E. 1988. A head movement approach to construct state noun phrases. Linguistics 26:909-929.

Roberts, I. 1991. Excorporation and minimality. Linguistic Inquiry 22:209-218.

Roberts, I. 2001. Head movement. In The handbook of contemporary syntactic theory, ed. M. Baltin \& C. Collins, 113-147. Oxford: Blackwell.

Rosen, C. 1990. Rethinking Southern Tiwa: The geometry of a triple agreement language, Language 66:669-731.

Schäfer, F. 2007. On the nature of anticausative morphology. Ph.D. dissertation, Universität Stuttgart.

Shlonsky, U. 1988. Government and binding in Hebrew nominals. Linguistics 26:951-976.

Shlonsky, U. 2004. The form of Semitic noun phrases. Lingua 114:1465-1526.

Stabler, E. 1996. Acquiring and parsing languages with movement. Ms., UCLA.

Stabler, E. 1997. Derivational minimalism. In Logical aspects of computational linguistics, ed. C. Retoré, 68-95. Heidelberg: Springer.

Stabler, E. 1998. Acquiring languages with movement. Syntax 1:72-97.

von Stechow, A. 1992. Kompositionsprinzipien und grammatische Struktur. In Biologische und soziale Grundlagen der Sprache, ed. P. Suchsland, 175-248. Tübingen: Niemeyer.

von Stechow, A., \& W. Sternefeld. 1988. Bausteine syntaktischen Wissens. Opladen, Germany: Westdeutscher Verlag.

Sternefeld, W. 1991. Syntaktische Grenzen. Chomskys Barrierentheorie und ihre Weiterentwicklungen. Opladen, Germany: Westdeutscher Verlag.

Sternefeld, W. 2006. Syntax. Tübingen: Stauffenburg.

Surányi, B. 2005. Head movement and reprojection. Annales Universitatis Scientiarum Budapestinensis de Rolando Eötvös Nominatae. Sectio Linguistica. ELTE Tomus 26:313342.

Svenonius, P. 1994. C-selection as feature-checking. Studia Linguistica 48:133-155.

Svenonius, P. 2004. On the edge. In Peripheries: Syntactic edges and their effects, ed. D. Adger, C. de Cat \& G. Tsoulas, 261-287. Dordrecht: Kluwer.

Szabolcsi, A. 1994. The noun phrase. In The structure of Hungarian (Syntax and Semantics 27), ed. F. Kiefer, 179-274. San Diego, CA: Academic Press.

Tappe, T. 1989. A note on split topicalization in German. In Syntactic phrase structure phenomena in noun phrases and sentences, ed. C. Bhatt, E. Löbel \& C. Schmidt, 159-179. Amsterdam: John Benjamins.

Travis, L. 1984. Parameters and effects of word order variation. Ph.D. dissertation, MIT, Cambridge, MA.

Williams, E. 1981. Argument structure and morphology. The Linguistic Review 1:81-114.

Williams, E. 1982. The NP cycle. Linguistic Inquiry 13:277-295.

Wunderlich, D. 1997. Cause and the structure of verbs. Linguistic Inquiry 27:27-68. 